\title{
Online internal short circuit detection for a large format lithium ion
}

\section{battery}

Xuning FENG ${ }^{1}$, Caihao $\mathrm{WENG}^{2}$, Minggao OUYANG ${ }^{1, *}$, Jing $\mathrm{SUN}^{2}$

1. State Key Laboratory of Automotive Safety and Energy, Tsinghua University, Beijing 100084, China.

2. Department of Naval Architecture and Marine Engineering, University of Michigan, Ann Arbor, MI 48109, USA.

(1)

8

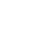

*Corresponding Author: ouymg@tsinghua.edu.cn

First author E-Mail: fxn07@mails.tsinghua.edu.cn

1 Address: State Key Laboratory of Automotive Safety and Energy, Tsinghua University,

2 Beijing 100084, China

23 Tel.: (86)-10-62773437

4 Fax: (86)-10-62785708

25 


\section{Abstract}

Early detection of an internal short circuit (ISC) in lithium ion batteries has become a crucial task for battery management, as ISC is believed to be the root cause of several large format lithium ion battery fire accidents. In this paper, a scheme of on-line detection of ISC is proposed, and the online ISC detection problem is addressed from a model parameterization and parameter estimation perspective. Using a 3D electrochemical-thermal-ISC coupled model, we explore the correlation between the measured voltage, current, and temperature data and the ISC status. It is identified that the abnormal depletion in the state-of-charge (SOC) and excessive heat generation associated with ISC affect the voltage and temperature responses, and that the correlation can be captured by a properly parameterized phenomenological model. The ISC detection is then recast as a parameter estimation problem, for which a model-based estimation algorithm is proposed and evaluated. It is shown that the estimation algorithm can track the parameter variations in real-time, thereby making it feasible to track ISC incubation status or to detect instantaneously triggered ISC. Moreover, it is observed that the recorded temperature profile is not affected by the location where the ISC occurs, due to the oval shape of the temperature distribution caused by anisotropic heat conduction of the battery core. Therefore, the proposed algorithm can detect the ISC, regardless of its physical location within the battery.

\section{Key words}

Lithium ion battery; Safety; Internal short circuit; Online detection; Parameter estimation.

\section{Introduction}

Given their high energy/power density and extended cycle life, lithium ion batteries have become one of the most popular choices for today's more-electrified powertrain systems [1-3]. 
However, several recent accidents associated with battery fire have raised great public awareness and concerns of the safety issues of lithium ion batteries [4]-[9].

All of the batteries that were involved in the accidents reported in [6]-[9] have high capacity and large formats in dimension. Large format batteries are favored by manufacturers because they reduce the cell number and pack complexity in battery pack design [10], thereby improving the reliability of a battery pack [11]. However, a large format battery is more vulnerable to safety problems because it contains more stored energy. Cooling is less effective because of the lower surface/volume ratio, which leads to higher non-uniformity in the temperature distribution within the cell [11]. A local hot spot, which may be triggered by an internal short circuit (ISC), can propagate throughout the whole cell, resulting in thermal runaway and fire [11].

An ISC is believed to be the root cause of the large format lithium ion battery fire in a series of accidents of Boeing 787 Dreamliner airplanes [8], [9]. In those cases, local heat generation, induced by the ISC, developed into thermal runaway in one of the large format batteries, resulting in cell-to-cell propagation and subsequent failure of the whole battery pack [8], [9]. Although there is no clear explanation on what has led to ISC in [8] and [9], an abundance of evidences and field experiences indicate that it takes a long incubation time before an ISC strikes [12], [13]. The ISC develops slowly during the incubation period as cycling continues [13]. The ISC-induced Joule heat will not develop into thermal runaway until the equivalent ISC resistance decreases to a substantially low level [13]. Before an ISC develops into a safety threat, it must be detected effectively to prevent the ensuing thermal runaway. The long time incubation makes it possible to perform early detection of ISC. 
Early detection of ISC is a great challenge for a battery management system (BMS) and

several research groups have made efforts to address this challenge. TIAX reported two technologies that can detect ISC early, according to [13]. However, no substantial details are available in the public domain due to the pending patents. With normal BMS sensors, the available signals recorded are the battery voltage, temperature, and current [14]. An ISC is usually accompanied by a voltage drop due to capacity depletion and a temperature rise due to additional heat generation [15]-[17]. The voltage and temperature responses may be used to detect faults such as ISC [18]. However, an ISC cannot be identified directly through the voltage and temperature responses [13] especially for large format batteries [19]. Therefore, model-based algorithms are required to interpret the ISC status from the voltage and temperature signals.

Correlating the ISC with a properly parameterized phenomenological model and then identifying the related parameters to infer the incubation status of ISC is a natural approach. With an established parametric model, the ISC detection problem can be recast as a parameter estimation problem, if the ISC incubation status can be correlated with model parameters. To this end, for ISC detection, we explore two phenomenological models: the Equivalent Circuit Model (ECM) $[20,21]$ and the Energy Balance Equation (EBE) proposed by Bernardi, Rao and Newman in $[22,23]$. The former model is used to predict the voltage behavior of lithium ion batteries [20,21], whereas the simplified latter model is used to calculate the temperature response $[24,25]$. Both models have been validated by experiments $[20,26]$ and have been used for different applications, such as battery SOC estimation [27-31] and SOH monitoring [32-36]. However, these models have not been used for ISC detection, to the best of the authors' knowledge. 
Voltage and temperature responses of an ISC battery cell from cycling are required to develop and evaluate the ISC detection algorithms. According to the literature, ISC can be experimentally created through 4 methods: (1) nail penetration [ 37 ], [38 ]; (2) rod crush/indentation [39], [40]; (3) inserting a temperature-controlled material inside the cell [17], [41]; and (4) inserting metal particles inside the cell [16]. However, it is difficult to design repeatable experiments that can emulate early stage incubation of field ISC failure. Most of the methods mentioned above will trigger a serious ISC that leads to immediate thermal runaway.

For our work on ISC detection, we use data generated by a high fidelity model instead of experimental data. Extensive research performed by several groups [19], [42], [43] has established an electrochemical- thermal-ISC coupled model that can capture the effects of ISC on the battery's electrochemical and thermal responses; this model will be referred as the et-ISC model in this paper. The et-ISC model has the advantage of easily simulating various levels of ISC at different locations within the battery. The electrochemical model used in the et-ISC model is based on the Dualfoil or the pseudo-two-dimensional (P2D) model developed by Doyle, Fuller and Newman [44-46], and it is regarded as a benchmark criterion to evaluate the quality of other simplified models [47-50]. This model can be expanded to include thermal effects by adding heat generation and heat transfer equations [51]-[57]. Moreover, an equivalent resistance is connected to the electrochemical- thermal model to simulate ISC [19], [42], [43]. All of the models in [43], [46], [52], [56], [57] have been validated by experimental data. Based on these models, one can establish a validated 3D electrochemical-thermal model to simulate the localized ISC inside a large format lithium ion battery cell during the ISC incubation process. 
In this paper, we use a 3D electrochemical-thermal model to simulate different cases of ISC.

The voltage and temperature responses of the et-ISC model are used to correlate the ISC status with the parameters in the ECM and EBE models, thereby establishing the validity of the proposed parametric approach for online detection of ISC. The model-based parameter estimation algorithm (RLS with forgetting factor in this study) is employed to transform the voltage and temperature responses into physical parameters, whose values are used for interpreting the ISC status. Various levels of ISC, including instantaneously triggered ISC and ISC at different locations within the cell, are set in the $3 \mathrm{D}$ electrochemical-thermal model to evaluate the proposed ISC detection method and algorithm. The numerical results indicate that model-based parameter estimation is indeed effective in detecting ISC, regardless of the physical location within the cell.

\section{An overview of the detection algorithm}

Fig. 1 shows the scheme of the ISC detection algorithm. Data for current $(I)$, voltage $(V)$, and temperature $(T)$ are collected and used as the input for the parameter estimation algorithm. A model-based parameter estimation algorithm is used to extract the physical parameters from the profiles of voltage, temperature, and current measurement. These physical parameters include internal resistance $R_{1}, R_{2}$, and battery capacitance $C$ in the ECM model and ohmic resistance $R_{\Omega}$ and the temperature derivative of the equilibrium potential $U_{T}$ in the EBE model. By applying the RLS algorithm with a forgetting factor to the parameterized ECM and EBE models, the estimation algorithm provides the values of the key parameters $R_{1}, R_{2}, C, R_{\Omega}$, and $U_{T}$. To demonstrate the utility of the ECM and EBE model for ISC detection, we must establish a correlation between the ISC status and the estimated parameters. Towards this end, and to evaluate the validity of the proposed algorithm, the et-ISC model is used to emulate various ISC scenarios in the algorithm 
development. In actual implementation, real-world battery data will be used instead of model-generated data.

This paper establishes the correlation between the ISC status and estimated parameters through simulation data generated by a validated 3D et-ISC model. We show that both the ECM and EBE models can be used for ISC detection, with a properly designed estimation algorithm. These two models rely on different data to interpret different physical phenomena: one focuses on electrical signals, and the other emphasizes the thermal behavior. Although each model alone can be used to detect ISC, as we demonstrate in this paper, combining the features identified using these two models will enhance the algorithm in terms of robustness against sensor failure, battery health degradation, and environmental condition changes. It will also reduce the possibility of false alarms.

In the remainder of the paper, an ISC detection algorithm for ISC detection through parameterized ECM and EBE models is developed and verified. The et-ISC model will be introduced in Sec. III, the parameter estimation algorithm will be described in Sec. IV, and the detection results and discussion will be presented in Sec. V.

\section{The internal short circuit model}

\subsection{Overview}

Fig. 2 shows the structure of the et-ISC model [19], [42], [43] used for ISC simulation in this paper. The geometry of the large format battery to be modeled is the same as the famous PHEV-2 type standardized in DIN SPEC 91252 [58] proposed by VDA (Verband der Automobilindustrie). The physical entities include the battery core, the battery shell and the battery pole, as indicated in Fig. 2(a). The physical dimensions of the target battery used for this study are listed in Table 1. 


\subsection{The pseudo-2D electrochemical model}

The electrochemical model is built according to [42]-[57] with the governing equations (1)-(10), as shown in Fig. 2(b) and listed in Table 2. The physical variables in the electrochemical model are listed in Table 3. The related physio-electrochemical parameters used in the electrochemical model are listed in Table 4 . The battery is assumed to have a nominal capacity of 27Ah with a $\mathrm{Li}_{y}(\mathrm{NiCoMn})_{1 / 3} \mathrm{O}_{2}$ cathode and a $\mathrm{Li}_{y} \mathrm{C}_{6}$ anode, where $y$ denotes the stoichiometry coefficients of the cathode and anode. The relationship between the open circuit potential $U_{\text {ref }}$ and the stoichiometry coefficient $y$ used in Eqn. (10) for both the cathode and anode is shown in Fig. 3. The nominal capacity $C_{\text {norm }}$ can be calculated by Eqn. (11), where $i_{1 \mathrm{C}}$ is the normalized current density, $A_{\text {core }}=L_{\mathrm{C}} \cdot H_{\mathrm{C}}$ denotes the active area of the battery core for one cell plate, $L_{\mathrm{C}}\left(H_{\mathrm{C}}\right)$ is the length (height) of the battery core defined in Table 1 , and $N$ is the number of stacked plates. The output voltage can be calculated by Eqn. (12) as the voltage difference between the positive electrode and the negative electrode in the solid phase. The voltage response of the electrochemical model can fit the experimental data of a real battery at different discharge rates, as shown in Fig. 4.

$$
\begin{gathered}
C_{\text {norm }}=i_{1 C} \cdot A_{\text {core }} \cdot N=i_{1 C} \cdot\left(L_{\mathrm{C}} \cdot H_{\mathrm{C}}\right) \cdot N \\
V=\left.\Phi_{s}\right|_{x=L_{C_{l}}+L_{n}+L_{s}+L_{p}+L_{A l}}-\left.\Phi_{s}\right|_{x=0}
\end{gathered}
$$

\subsection{The 3D thermal model}

Table 5 collects all of the governing equations for the 3D thermal model according to [43], [55]-[57]. The heat generation rate $Q$ in Eqn. (13) can be calculated by Eqn. (14), where $Q_{\text {rev }}, Q_{\text {irr }}$, $Q_{\text {ohm, }}$ and $Q_{\text {short }}$ denote the reversible heat generation, irreversible heat generation, Ohmic heat generation, and the heat generation caused by ISC, respectively, and they can be calculated by Eqns. (15)-(18), according to [43], [55]-[57]. $Q_{\text {short }}=I_{\text {short }}^{2} R_{\text {short }}$ at the location where ISC occurs, 
whereas $Q_{\text {short }}$ is equal to zero at other normal places without ISC. $I_{\text {short }}$ denotes the current caused by ISC, and $R_{\text {short }}$ denotes the equivalent resistance when ISC occurs. The detailed treatment for ISC in both the electrochemical model and the thermal model will be discussed in Sec. 3.5. Thermal resistant layers, e.g., the aluminum plastic foil and the air gap, exist between the battery core and the battery shell, as shown in Fig. 2(c). The heat conductions at the thermal resistant layers are modeled by Eqn. (19) and Eqn. (20).

The physical parameters used in the thermal model are listed in Table 6 . The battery core is assumed to have the same anisotropic heat conductivities as in [56], [60,61], the values of which are set referring to [61]. As there is always an air gap between the battery core and the battery shell in a typical battery structure, therefore a 5-mm-thick thermal resistant layer filled with air is set at the top of the battery core. The other sides and the bottom of the battery core are assumed to be wrapped by $\mathrm{Al}$ plastic film, referring to the battery structure in [62]. The average heat convection coefficient is set as $5 \mathrm{~W} / \mathrm{m}^{2} \cdot \mathrm{K}$, indicating natural convection, and the ambient temperature is set as $25^{\circ} \mathrm{C}$ surrounding the battery shell. The mesh grids of the $3 \mathrm{D}$ thermal model are shown in Fig. 5.

\subsection{Coupled electrochemical-thermal model}

The P2D electrochemical model and the 3D thermal model can be coupled according to Fig. 2(d), referring to [42], [65]. The coupled electrochemical-thermal model is built in Comsol Multiphysics $^{\circledR}$ ver 4.4. The data of temperature under different current rates are collected and are shown in Fig. 6. The model generated data can fit the experimental results with $h=0.38 \mathrm{~W} / \mathrm{m}^{2} \cdot \mathrm{K}$, as reported in [57], especially for the current rates less than 1C. The accuracy is deemed sufficient to 
simulate the temperature response in this paper because the current profiles used in subsequent sections are always less than $1 \mathrm{C}$.

\subsection{The ISC treatment in the model}

Fig. 7 shows the ISC treatment in the electrochemical-thermal model, referring to [19], [42], [43]. In this study, the area of ISC is set to be $2 \mathrm{~mm} \times 2 \mathrm{~mm}$, located at the coordinate of $(\Delta x, \Delta y, \Delta z)$ with $(0,0,0)$ being the center of the battery core. The equivalent resistance of the ISC is set as $R_{\text {short }}$, which varies for different cases to test the detection algorithms. The ISC current, $I_{\text {short, }}$, satisfies Ohm's law as in Eqn. (21), where $V$ is the voltage output of the model as in Eqn. (12).

$$
I_{\text {short }}=\frac{V}{R_{\text {short }}}
$$

$I_{\text {short }}$ changes the actual current profile $I_{\text {app }}$ applied on the electrochemical model and thus influences the electrode current density $i_{\mathrm{s}} . I_{\text {app }}$ equals $I_{\text {load }}$, the load current, when there is no ISC, whereas $I_{\text {app }}$ equals the sum of $I_{\text {load }}$ and $I_{\text {short }}$ when ISC occurs inside the battery, as in Eqn. (22). $I_{\text {app }}$ is the spatial integration of the electrode current density $i_{\mathrm{s}}$, as in Eqn. (23); therefore, $I_{\text {short }}$ can be coupled in the electrochemical model.

$$
\begin{gathered}
I_{\text {app }}= \begin{cases}I_{\text {load }}, & (w / o \text { ISC }) \\
I_{\text {load }}+I_{\text {short }},(w / I S C)\end{cases} \\
I_{\text {app }}=\iint i_{\mathrm{s}} d A=N \cdot A_{\text {core }} \cdot i_{\mathrm{s}}
\end{gathered}
$$

The local heat generation caused by ISC can be calculated by Eqn. (18) in Table 5. Local heat accumulation raises the temperature near the ISC point, as shown in Fig. 7. Three probes, $T_{\mathrm{S} 1}$, $T_{\mathrm{S} 2}$, and $T_{\mathrm{S} 3}$, are applied in the 3D-thermal model to monitor the temperature at the center of the battery surface, the core center, and the ISC point, respectively, as shown in Fig. 7. 
by thermocouple placed at the surface center as in practical application.

\subsection{Model responses}

Fig. 8 shows the outputs of the model during $1 \mathrm{C}$ charge/discharge cycle with and without ISC. The equivalent resistance for ISC is $R_{\text {short }}=20 \Omega$. Note that the voltage response in the case of ISC is very similar to the case without ISC. Meanwhile the temperature variations are shown in both cases due to the charge/discharge activities. Therefore, direct detection of ISC through signal processing of voltage and temperature is very difficult. As a result, we pursue a model-based online parameter estimation approach to enable ISC detection.

\section{The parameter estimation algorithm}

\subsection{Parametric model}

Online parameter estimation requires a parametric model in the form of Eqn. (24), where $Y$ is the observation, $\theta$ is the parameter to be estimated, $\Phi$ is the regressor [66]. $k$ is the time index and the sampling time is $t_{\mathrm{s}}$ from the $\mathrm{Comsol}^{\circledR}$ simulation output.

$$
Y(k)=\theta(k)^{T} \Phi(k)
$$

The ECM model, as shown in Fig. 1, involves the discretized equations (25) and (26), where $R_{1}, R_{2}$ and $C$ are the physical parameters that have correlations with the ISC status. To use the ECM model for ISC detection, Eqn. (27), representing the standard parametric model (24), is obtained by substituting Eqn. (25) into (26). Next, we apply online parameter estimation of $\theta$ in the ECM model; subsequently, the estimated $\theta$ is used to determine $R_{1}, R_{2}$ and $C$.

$$
V_{R C}(k)=\alpha \cdot V_{R C}(k-1)+R_{2}(1-\alpha) \cdot I(k-1), \alpha=\exp \left(-1 / R_{2} C\right)
$$




$$
V(k)=O C V(k)-R_{1} \cdot I(k)-V_{R C}(k)
$$

$$
\left\{\begin{array}{l}
Y(k)=V(k)-O C V(k) \\
\theta(k)=\left(\alpha, R_{1},\left[\alpha R_{1}-R_{2}(1-\alpha)\right]\right) \\
\Phi(k)=([V(k-1)-O C V(k-1)],-I(k), I(k-1))
\end{array}\right.
$$

The open circuit voltage (OCV) varies with the state of charge (SOC), as shown in Fig. 9.

The SOC is assumed to be calculated by Eqn. (28), where $\operatorname{SOC}(k)$ is the estimated SOC at time

$k \cdot t_{s}, \operatorname{SOC}(0)$ is the initial SOC, $t_{s}$ is the sampling time, and $I_{\mathrm{SOC}}=I_{\text {load }}$ when calculating the SOC.

Given the relationship between the SOC and OCV, OCV is treated as known in the algorithm.

$$
\operatorname{SOC}(k)=\operatorname{SOC}(0)+\sum_{l=1}^{k}\left(\frac{I_{\mathrm{SOC}}(k) \cdot t_{\mathrm{s}}}{C_{\mathrm{norm}}}\right)
$$

Similarly, given the continuous form of the EBE, as in Eqn. (29), where the parameters are

defined in Table 7, a parametric model for estimating $R_{\Omega}$ (the Ohmic resistance) and $U_{T}$ (the

temperature sensitivity of equilibrium potential) can be derived. The discretized form of the EBE

is given by Eqn. (30), where $T_{\mathrm{S} 1}$ and $T_{\mathrm{S} 2}$ represent the temperature at the center of the battery

$$
\dot{T}_{\mathrm{S} 2}(k)=\frac{1}{M C_{p}}\left(I(k)^{2} \cdot R_{\Omega}+I(k) T_{\mathrm{S} 2}(k) \cdot U_{T}-h A\left(T_{\mathrm{S} 1}(k)-T_{\infty}\right)\right)
$$

$$
T_{\mathrm{S} 2}=T_{\mathrm{S} 1}+X\left(T_{\mathrm{S} 1}-T_{\infty}\right)
$$




$$
\left\{\begin{array}{l}
Y(k)=M C_{p}(1+X) \dot{T}_{\mathrm{S} 1}(k)+h A\left(T_{\mathrm{S} 1}(k)-T_{\infty}\right) \\
\theta(k)=\left(R_{\Omega}, U_{T}\right) \\
\Phi(k)=\left(I^{2}(k), I(k) \cdot\left[T_{\mathrm{S} 1}(k)+X\left(T_{\mathrm{S} 1}(k)-T_{\infty}\right)\right]\right)
\end{array}\right.
$$

The temperature derivative $\dot{T}_{\mathrm{S} 1}(k)$ is not directly measured, but numerically calculated by 1$)$ fitting 2 n points nearest to time $k$ using simple linear regression, as in Eqn. (33), where $a$ and $b$ are derived through least squares; and 2) setting the temperature derivative $\dot{T}_{\mathrm{S} 1}(k)$ equal to the derivative $a$ of the fitting function.

$$
T_{\mathrm{S} 1}(k)=a k+b
$$

\subsection{Parameter estimation algorithm}

We can employ the recursive least squares (RLS) algorithm with a forgetting factor $\beta$ to estimate the parameter $\theta$ to detect the occurrence of ISC. Eqns. (24) and (34)-(37) are the standard equations for the RLS algorithm referring to [66-68].

$$
\begin{gathered}
Y(k)=\theta(k)^{T} \Phi(k) \\
E(k)=Y(k)-\theta(k-1)^{T} \Phi(k) \\
\theta(k)=\theta(k-1)+K(k) E(k) \\
K(k)=\frac{P(k-1) \Phi(k)}{\beta+\Phi(k)^{T} P(k-1) \Phi(k)} \\
P(k)=\frac{P(k-1)-K(k) \Phi(k)^{T} P(k-1)}{\beta}
\end{gathered}
$$

The updates of the parameter $\theta$ and the covariance $P$ are stopped when the current $I(k)>I_{\text {Pstop }}$ for some threshold $I_{\text {Pstop }}$, because the model is only validated for low charging current.

$$
\left\{\begin{array}{l}
\theta(k)=\theta(k-1) \\
P(k)=P(k-1)
\end{array}, \text { no updating when } I(k)>I_{\text {Pstop }}\right. \text { in the thermal model Eqns. (29)-(32). }
$$

\subsection{Data for algorithm evaluation}

Federal Urban Drive Cycle (FUDS) [69] is used as the current input of the ISC model to guarantee persistent excitation, a condition that will help parameter estimation. FUDS can also 
simulate practical working conditions of the battery. The model outputs of $V$ and $T$ under 3 repeated FUDS cycles is shown in Fig. 10. $V$ and $T$ have sampling accuracies of $1 \mathrm{mV}$ and $0.01^{\circ} \mathrm{C}$, respectively. White noise with Gaussian distribution $N\left(0, \Sigma_{V}\right)$ and $N\left(0, \Sigma_{T}\right)$ have been added into the sampled signal $V$ and $T$ to emulate practical conditions. Finally, the parameters of interest and their values used in simulation are summarized in Table 7.

\section{Detection results and discussion}

\subsection{Overview}

To evaluate the effectiveness of the model-based parameter estimation algorithm for ISC detection, data were generated by the et-ISC model for different scenarios (as in Table 8) with the following specifics: 1) Case 1-Case 5 are established with various degrees of ISC to test the capability of the algorithm in detecting different levels of ISC; 2) Case 6 and Case 7 are established to test the capability of the algorithm to detect the instantaneously-triggered ISC during cycling; and 3) Case 8-Case 13 are established to evaluate the algorithm when the ISC occurs at different locations within the battery. In addition, the initial conditions for all of the simulations are listed in Table 9.

The maximum temperature at the ISC point $\left(T_{\mathrm{S} 3}\right.$ in Fig. 7$)$ during cycling is given in the last column of Table 8 to confirm that the cases are indeed reflecting the ISC at different incubation stages. The maximum temperature for ISC with an equivalent resistance of $R_{\text {short }}=10 \Omega$ is $53^{\circ} \mathrm{C}$. A higher temperature $\left(>55^{\circ} \mathrm{C}\right)$ may lead to severe battery capacity fading, and the self-heating could be triggered at $T>85^{\circ} \mathrm{C}$, as reported in [70]. Therefore, it would be helpful if early ISC can be detected when the equivalent ISC resistance is larger than $10 \Omega$. 


\subsection{Detection of ISC at various incubation stages}

Cases 1-5 are established to test the capability of the algorithm in detecting different levels of ISC. Fig. 11 shows the detection results based on the ECM model using voltage measurements.

The voltage curve for more severe ISC (with lower $R_{\text {short }}$ ) will be slightly lower than those with less severe ISC, as shown in Fig. 11(a), due to the extra SOC depletion associated with ISC. Fig. 11(b) shows the estimation results for the parameters in the ECM model using Eqns. (24), (27), and (34)-(37). The values for the estimated $R_{1}, R_{2}$, and $C$ are listed in Table 10. As shown in Fig. 11(b) and Table 10, as $R_{\text {short }}$ decreases, $R_{1}$ changes slightly, indicating minor changes in the DC resistance during ISC. The values of $R_{2}$ and $C$ increase $355 \%$ and $78 \%$ (173\% and 35\%), respectively, for the ISC resistance $R_{\text {short }}=10 \Omega(20 \Omega)$. The excessive increments of $R_{2}$ and $C$ are caused by the accumulating voltage depletion due to ISC. The results indicate that the algorithm may detect ISC based on the ECM when $R_{\text {short }}$ is as high as $20 \Omega$.

Fig. 12(a) shows the 3-D temperature distributions for Case 1 (no ISC) and Case 4 $\left(R_{\text {short }}=20 \Omega\right)$ before and after 3 FUDS cycles. A hot spot caused by local ISC heating can be seen at the center of the battery core for Case 4. Fig. 12(b) compares the temperature responses for Cases 1-5. The center temperature ( $T_{\mathrm{S} 2}$ in Fig. 7 ) shows different levels of temperature rise with different $R_{\text {short, }}$ whereas the surface temperature curves show some drifts with different temperature rise/drop rates. Fig. 12(c) is the detection results based on the EBE model, Eqns. (24), (32), and (34)-(38). As shown in Fig. 12(c) and Table 10, as $R_{\text {short }}$ decreases, the absolute values of $R_{\Omega}$ and $U_{T}$, which represent the average heat generation during operation, show obvious increases due to the excessive heat generation caused by the ISC. The absolute values of $R_{\Omega}$ and $U_{T}$ increase $493 \%$ and $637 \%$ ( $243 \%$ and $331 \%$ ), respectively, for the ISC resistance $R_{\text {short }}=10 \Omega(20 \Omega)$. In addition, observable increases (67\% and 107\%) in the absolute values of $R_{\Omega}$ and $U_{T}$, respectively, 
for $R_{\text {short }}=50 \Omega$ indicates that the algorithm may detect ISC based on the EBE, even when $R_{\text {short }}$ is as high as $50 \Omega$.

The results establish that both models can be used for ISC detection, with EBE having higher sensitivity for mild ISC cases.

\subsection{Detection of instantaneously triggered ISC}

For Case 6 and Case 7, the et-ISC model is established to test the capability of the algorithm to detect an instantaneously triggered ISC during cycling. The ISC is presumed to be triggered at time $t=3431 \mathrm{~s}$. Fig. 13(a) illustrates that no local hot spot occurs inside the battery between $0-3430$ s in the simulation of Case 6, whereas a continuous temperature rise is observed once the ISC is triggered. Fig. 13(b) shows the voltage and temperature responses for Case 6 and Case 7. The temperature at the battery center $\left(T_{\mathrm{S} 2}\right.$ in Fig. 7$)$ rises sharply, whereas the surface temperature ( $T=T_{\mathrm{S} 1}$ in Fig. 7) starts to rise slowly when ISC is triggered. The estimation results of the algorithm can adapt to the instantaneously triggered ISC, as shown in Fig. 13(c), Fig. 13(d) and Table 11 . The values of $R_{2}$ and $C$ increase by $131 \%$ and $145 \%$ (9\% and $\left.62 \%\right)$, respectively, and the average absolute values of $R_{\Omega}$ and $U_{T}$ in one FUDS cycle increase $433 \%$ and $494 \%(96 \%$ and $292 \%$ ), respectively, after ISC is triggered for $R_{\text {short }}=10 \Omega(20 \Omega)$. The EBE model-based algorithm detects the instantaneously triggered ISC more quickly than the ECM-based algorithm when ISC is instantaneously triggered.

\subsection{Detection of ISC at different locations}

The 3D et-ISC model provides a convenient means for us to investigate the effects of ISC when it occurs at different locations within a cell. Case 5 and Cases 8-13 provide simulation results corresponding to ISC at different locations. We choose $R_{\text {short }}=10 \Omega$ because in this case, the ISC can cause the most severe non-uniformity of temperature distribution. Fig. 14(a) illustrates the 
temperature distribution at the end of 3 FUDS cycles for Case 5 and Case 13. The maximum temperature of Case $13\left(53.18^{\circ} \mathrm{C}\right)$ is slightly higher than that of Case $5\left(48.00^{\circ} \mathrm{C}\right)$, because the heat dissipation at the corner is poorer than at the center, as reported in [37]. Fig. 14(b) shows the voltage and temperature responses for Case 5 and Cases 8-13. The voltage responses are quite similar, which leads to similar estimation results based on the ECM model, as shown in Fig. 14(c) and Table 12 . There is at most a $0.2^{\circ} \mathrm{C}$ difference in temperature responses at the battery surface. Moreover, the temperature rise rates are similar, indicating similar inputs of $\dot{T}_{\mathrm{S} 1}(k)$ and $Y(k)$ as those in (32); therefore, the estimation results based on the EBE model are quite close, as presented in Fig. 14(d) and Table 12.

Fig. 15 helps explain the reason for the similar temperature responses for cases with ISC at different locations. Figs. 15(a) and (b) shows the temperature distributions for Case 5 and Case 10, respectively, at the end of 3 FUDS cycles $(t=4116 \mathrm{~s})$. The anisotropic thermal conductivity of the battery core $\left(\lambda_{x}=\lambda_{y}=21 \mathrm{~W} / \mathrm{m} \cdot \mathrm{K}\right.$ and $\lambda_{z}=0.5 \mathrm{~W} / \mathrm{m} \cdot \mathrm{K}$ in Table 6) leads to an ellipsoid temperature distribution surrounding the ISC point, as shown in Fig. 15(a) and Fig. 15(b). Therefore, the oval isothermal line in the intersection $x-z$ plane at $y=0$ leads to similar responses of the surface temperature $T=T_{\mathrm{S} 1}$, as illustrated in Figs. 15(c) and (d). Here, in Figs. 15(c) and (d), for both cases, the temperature $T=T_{\mathrm{S} 1}$ recorded at the battery surface is approximately $30.8^{\circ} \mathrm{C}$ according to the isothermal line.

In summary, with only one temperature sensor $T_{\mathrm{S} 1}$ located at the center of the battery surface, the proposed detection algorithm leads to similar detection results, regardless of the ISC locations. This result is an advantage of the proposed algorithm, in the sense that we do not need to incorporate the location sensitivity in the algorithm development. If, however, one wishes to 
detect not only the ISC status but also its location, then more temperature sensors must be installed at different locations on the battery surface.

\section{Conclusion}

This paper investigated the detectability of ISC in a large format lithium ion battery for BMS using only the measurements of current, voltage, and temperature (at the center of the battery surface). We demonstrated a successful ISC detection algorithm through a model-based parameter estimation algorithm.

A 3D electrochemical-thermal model was built to simulate various ISC scenarios inside a large format lithium ion battery. The model can predict the voltage and temperature responses of the battery with or without ISC. The RLS algorithm with forgetting factor was applied to estimate the critical parameters in the parameterized ECM and the EBE models. The changes in the estimated parameters, namely the parallel-connected $R_{2}$ and $C$ in ECM, ohmic resistance $R_{\Omega}$ and temperature derivative of equilibrium potential $U_{T}$ in EBE, can be used as indicators of ISC. The same algorithm can detect the ISC status in the incubation process or the ISC that is triggered instantaneously. We also showed that an ISC can be detected regardless of where it occurs using the temperature measured at the surface center. To detect the ISC location within a large format lithium ion battery, additional sensors must be employed.

Our future research on ISC detection will focus on the following: 1) conducting experiments to validate the ISC detection algorithm; and 2) characterizing optimized temperature sensor placement to detect the ISC location. 


\section{Acknowledgement}

This work was supported by US-China Clean Energy Research Center-Clean Vehicle Consortium (CERC-CVC). The CERC-CVC in China side is supported by the MOST (Ministry of Science and Technology) of China under the contract of No. 2014DFG71590, and in U.S. side supported by the Department of Energy under Award Number DE-PI0000012. The first author appreciates the funding from China Scholarship Council.

\section{References}

[1] Xue N, Du W, Greszler TA, Shyy W, Martins JRRA. Design of a lithium-ion battery pack for PHEV using a hybrid optimization method. Applied Energy, 2014, 115: 591-602.

[2] Ping P, Wang Q, Huang P, Sun J, Chen C. Thermal behavior analysis of lithium-ion battery at elevated temperature using deconvolution method. Applied Energy, 2014, 129: 261-273.

[3] Wang T, Tseng KJ, Zhao J, Wei Z. Thermal investigation of lithium-ion battery module with different cell arrangement structures and forced air-cooling strategies. Applied Energy, 2014, 134: $229-238$.

[4] Wang Q, Ping P, Zhao X, Chu G, Sun J, Chen C. Thermal runaway caused fire and explosion of lithium ion battery. J. Power Sources, 2011, 196: 210-224.

[5] Beauregard GP. Report of investigation: hybrids plus plug in hybrid electric vehicle. eTec, Phoenix, AZ, Tech. Rep., June 26, 2008.

[6] Smith B. Chevrolet volt battery incident summary report. National Highway Traffic Safety Administration, DC, Rep. No. DOT-HS-811-573, Jan. 20, 2012.

[7] Willard N, He W, Hendricks C, Pecht M. Lessons learned from the 787 dreamliner issue on lithium-ion battery reliability. Energies, 2013, 6:4682-4695.

[8] Aircraft incident report: auxiliary power unit battery fire, Japan airlines Boeing 787, JA 829J, Boston, Massachusetts, January 7, 2013. National Transportation Safety Board, DC, Rep. No. PB2014-108867, Nov. 21, 2014. 
[9] Goto N. Aircraft serious incident investigation report: all Nippon airways Co. Ltd. JA804A. Japan Transport Safety Board, Tokyo, Japan, Rep. No. AI2014-4, Sep. 25, 2014.

[10] Lee KJ, Smith K, Pesaran A, Kim GH, "Three dimensional thermal-, electrical-, and electro chemical-coupled model for cylindrical wound large format lithium-ion batteries," J. Power Sources, 2013, 241: 20-32.

[11] Kim GH, Pesaran A, Spotnitz R. A three-dimensional thermal abuse model for lithium-ion cells. J. Power Sources, 2007, 170: 476-489.

[12] Doughty DH, Pesaran A. Vehicle battery safety roadmap guidance. National Renewable Energy Laboratory, Golden,CO, Subcontract Rep. No. NREL/SR-5400-54404, Oct. 2012.

[13] Barnett B. Technologies for detection and intervention of internal short circuits in Li-ion batteries. Presented at the $5^{\text {th }}$ Annual Knowledge Foundation Conf. Battery Safety 2014, Washington D.C., US, Nov. 11-14, 2014.

[14] Lu L, Han X, Li J, Hua J, Ouyang M. A review on the key issues for lithium-ion battery management in electric vehicles. J. Power Sources, 2013, 226: 272-288.

[15] Ramadass P, Fang W, Zhang Z. Study of internal short in a Li-ion cell I: Test method development using infra-red imaging technique. J. Power Sources, 2014, 248: 769-776.

[16] Santhanagopalan S, Ramadass P, Zhang Z. Analysis of internal short-circuit in a lithium ion cell. J. Power Sources, 2009, 194: 550-557.

[17] Orendorff CJ, Roth EP, Nagasubramanian G. Experiemental triggers for internal short circuits in lithium-ion cells. J. Power Sources, 2011, 196: 6554-6558.

[18] Xia B, Chen Z, Mi C, Robert B. External short circuit fault diagnosis for lithium ion batteries. Presented at Transportation Electrification Conference and Expo (ITEC), pp.1-7, 2014, Deaborn, MI, US.

[19] Kim GH, Smith K, Ireland J, Pesaran A. Fail-safe design for large capacity lithium-ion battery systems. J.Power Sources, 2012, 210: 243-253.

[20] Hu X, Li S, Peng H. A comparative study of equivalent circuit models for Li-ion batteries. J. Power Sources, 2012, 198: 359-367. 
[21] Liaw BY, Nagasubramanian G, Jungst RG, Doughty DH. Modeling of lithium ion cells-A simple equivalent-circuit model approach. Solid State Ionics, 2004, 175: 835-839.

[22] Bernardi D, Pawikowski E, Newman J. A general energy balance for battery systems. J. Electrochem. Soc., 1985, 132(1): 5-12.

[23] Rao L, Newman J. Heat-generation rate and general energy balance for insertion battery systems. J. Electrochem. Soc., 1997, 144(8): 2697-2704.

[24] Chen Y, Evans JW. Heat transfer phenomena in Lithium/polymer-electrolyte batteries for electric vehicle application. J. Electrochem. Soc., 1993, 140(7): 1833-1838.

[25] Chen SC, Wang YY, Wan CC. Thermal analysis of spirally wound lithium batteries. J. Electrochem. Soc., 2006, 153(4): A637-A648.

[26] Liu G, Ouyang M, Lu L, Li J, Han X. Analysis of the heat generation of lithium-ion battery during charging and discharging considering different influencing factors. J. Them. Anal. Calorim., 2014, 116: 1001-1010.

[27] Xiong R, Sun F, He H, et al. A data-driven adaptive state of charge and power capability joint estimator of lithium-ion polymer battery used in electric vehicles[J]. Energy, 2013, 63: 295-308.

[28] Dai H, Wei X, Sun Z, Wang J, Gu W. Online cell SOC estimation of Li-ion battery packs using a dual time-scale Kalman filtering for EV applications. Applied Energy, 2012, 95: 227-237, 2012.

[29] Weng C, Sun J, Peng H. A unified open-circuit-voltage model of lithium-ion batteries for state-of-charge estimation and state-of-health monitoring. J. Power Sources, 2014, 258: 228-237, 2014.

[30] Xing Y, He W, Pecht M, Tsui KL. State of charge estimation of lithium-ion batteries using the open-circuit voltage at various ambient temperatures. Applied Energy, 2014, 113: 106-115.

[31] Sun F, Xiong R, He H. Estimation of state-of-charge and state-of-power capability of lithium-ion battery considering varying health conditions. J. Power Sources, 2014, 259: 166-176. 
[32] Waag W, Kaebitz S, Sauer DU. Experimental investigation of the lithium ion battery impedance characteristic of various conditions and aging status and its influence on the application. Applied Energy, 2013, 102: 885-897.

[33] Chiang YH, Sean WY, Ke JC. Online estimation of internal resistance and open-circuit voltage of lithium-ion batteries in electric vehicles. J. Power Sources, 2011, 196: 3921-3932.

[34] Fleischer C, Waag W, Heyn H, Sauer DU. Online adaptive battery impedance parameter and state estimation considering physical principles in reduced order equivalent circuit battery models: Part 2. Parameter and state estimation. J. Power Sources, 2014, 262: 457-482.

[35] Plett GL. Extended Kalman filtering for battery management systems of LiPB-based HEV battery packs, Part 3. State and parameter estimation. J. Power Sources, 2004, 134: 277-292.

[36] Lin X, Perez HE, Siegel JB, Stefanopoulou AG. Online parameterization of lumped thermal dynamics in cylindrical lithium ion batteries for core temperature estimation and health monitoring. IEEE Trans. on Control Systems Technology, 2013, 21(5): 1745-1755.

[37] Maleki H and Howard JN. Internal short circuit in Li-ion cells. J. Power Sources, 2009, 191: $568-574$

[38] Feng X, Sun J, Ouyang M, Wang F, He X, Lu L, Peng H. Characterization of penetration induced thermal runaway propagation process within a large format lithium ion battery module. J. Power Sources, 2015, 275: 261-273.

[39] Lamb J, Orendorff CJ. Evaluation of mechanical abuse techniques in lithium ion batteries. J. Power Sources, 2014, 247: 189-196.

[40] Sahraei E, Campbell J, Wierzbicki T. Modeling and short circuit detection of 18650 Li-io cells under mechanical abuse conditions. J. Power Sources, 2012, 220: 360-372.

[41] Keyser M, Long D, Ireland J, Pesaran A, Darcy E, Shoesmith M, McCarthy B. Internal short circuit instigator in lithium ion cells. Presented at the $4^{\text {th }}$ Annual Knowledge Foundation Conf. Battery Safety 2013, San Diego, CA, Nov. 14, 2013.

[42] Zhao W, Luo G, Wang CY. Modeling nail penetration process in large-format Li-ion cells. J. Electrochem. Soc., 2014, 162(1): A207-A217. 
[43] Fang W, Ramadass P, Zhang Z. Study of internal short in a Li-ion cell II: Numerical investigation using a 3D electrochemical-thermal model. J. Power Sources, 2014, 248: 1090-1098.

[44] Doyle M, Fuller TF, Newman J. Modeling of galvanostatic charge and discharge of the Lithium/polymer/insertion cell. J. Electrochem. Soc.1993, 140(6): 1526-1533.

[45] Fuller TF, Doyle M, Newman J. Simulation and optimization of the dual Lithium ion insertion cell. J. Electrochem. Soc. 1994, 141(1), 1-10.

[46] Doyle M, Newman J. Comparison of modeling predictions with experimental data from plastic lithium ion cells. J. Electrochem. Soc., 1996, 143(6): 1890-1903.

[47] Chaturvedi NA, Klein R, Christensen J, Ahmed J, Kojic A. Algorithm for advanced battery management systems: modeling, estimation and control challenges for lithium ion batteries. IEEE Control Systems Magazine, 2010, 30(3): 49-68.

[48] Chaturvedi NA, Klein R, Christensen J, Ahmed J, Kojic A. Modeling, estimation, and control challenges for lithium-ion batteries. American Control Conference, Marriott Waterfront, Baltimore, MD, USA, June 30-July 02, 2010, pp. 1998-2002.

[49] Klein R. Chaturvedi NA, Christensen J, Ahmed J, Findeisen R, Kojic A. Electrochemical mode based observer design for a Lithium-ion battery. IEEE Transactions on Control Systems Technology. 2013, 21(2): 289-301.

[50] Han X, Ouyang M, Lu L, Li J. Simplification of physics-base electrochemical model for lithium ion battery on electric vehicle. Part II: pseudo-two-dimensional model simplification and state of charge estimation. J. Power Sources, 2015, 278: 814-825.

[51] Smith K. Wang CY. Power and thermal characterization of a lithium-ion battery pack for hybrid-electric vehicles. J. Power Sources, 2006, 160: 662-673.

[52] Fang W. Kwon OJ, Wang CY. Electrochemical-thermal modeling of automotive Li-ion batteries and experimental validation using a three-electrode cell. Int. J. Energy Res. 2010, 34: $107-115$

[53] Srinivasan V, Wang CY. Analysis of electrochemical and thermal behavior of Li-ion cells. J. Electrochem. Soc., 2003, 150(1): A98-A106. 
[54] Christensen J, Cook D, Albertus P. An efficient parallelizable 3D thermos-electrochemical model of a Li-ion cell. J. Electrochem. Soc., 2013, 160(11): A2258-A2267.

[55] Cai L, White RE. Mathematical modeling of a lithium ion battery with thermal effects in COMSOL Inc. Multiphysics (MP) software. J. Power Sources, 2011, 196: 5985-5989.

[56] Song L, Evans JW. Electrochemical-thermal model of lithium polymer batteries. J. Electrochem. Soc., 2000, 147(6): 2086-2095.

[57] Ye Y, Shi Y, Cai N, Lee J, He X. Electro-thermal modeling and experimental validation for lithium ion battery. J. Power Sources, 2012, 199: 227-238.

[58] Electrically propelled road vehicles-Battery systems-Dimensions for Lithium-Ion-Cells, DIN SPEC 91252, Jan. 2011.

[59] Material property for 1:1 EC:DEC / LiPF6 in material database of Comsol Multiphysics ver4.4, 2014.

[60] Feng X, He X, Lu L, Ouyang M. Research on simplification of simulating the heat conduction in the lithium-ion battery core. Presented in EVS27, Barcelona, Spain, 2013, pp. $1-12$.

[61] Zhang J, Wu B, Li Z, Huang J. Simultaneous estimation of thermal parameters for large-format laminated lithium-ion batteries. J. Power Sources, 2014, 259: 106-116.

[62] Feng X, Sun J, Ouyang M, He X, Lu L, Han X, Fang M, Peng H. Characterization of large format lithium ion battery exposed to extremely high temperature. J. Power Sources, 2014, 272: 457-467.

[63] Material property for Aluminum in material database of Comsol Multiphysics ver4.4, 2014.

[64] Lienhard JH IV, Lienhard JH V. Heat conduction concept, thermal resistance, and the overall heat transfer coefficient. A Heat Transfer Text Book, $3^{\text {rd }}$ edition. Cambridge, MA: Phlogiston Press, Chap. 2, Sec. 1, pp. 62-78.

[65] Thermal modeling of a cylindrical Li-ion battery in 2D. User Manual of Comsol Multiphysics, ver 4.4, 2014.

[66] Ioannou PA, Sun J. "On-line parameter estimation." in Robust Adaptive Control, Dover edition, Mineola, NY: Dover Publiaions, Inc., Chap. 4, pp.144-249. 
[67] Xiong R, Sun F, Gong X, et al. A data-driven based adaptive state of charge estimator of lithium-ion polymer battery used in electric vehicles. Appl Energy, 2014, 113: 1421-1433.

[68] Sun F, Xiong R, He H. A systematic state-of-charge estimation framework for multi-cell battery pack in electric vehicles using bias correction technique. Applied Energy, http://dx.doi.org/10.1016/j.apenergy.2014.12.021.

[69] Electric vehicle battery test procedures manual, USABC Manual, ver2, Jan. 1996. Available: http://avt.inl.gov/battery/pdf/usabc_manual_rev2.pdf

[70] Feng X, Fang M, He X, Ouyang M, Lu L, Wang H, Zhang M. Thermal runaway features of large format prismatic lithium ion battery using extended volume accelerating rate calorimetry. J. Power Sources, 2014, 255: 294-301. 


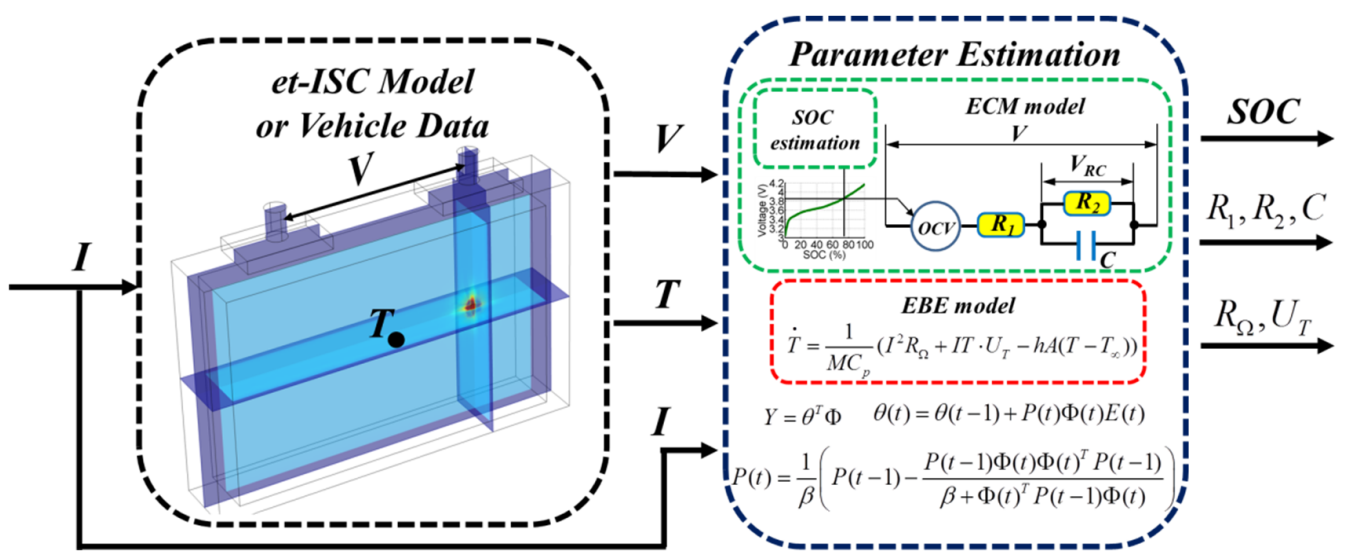

Figure 1 The scheme of the ISC detection algorithm.

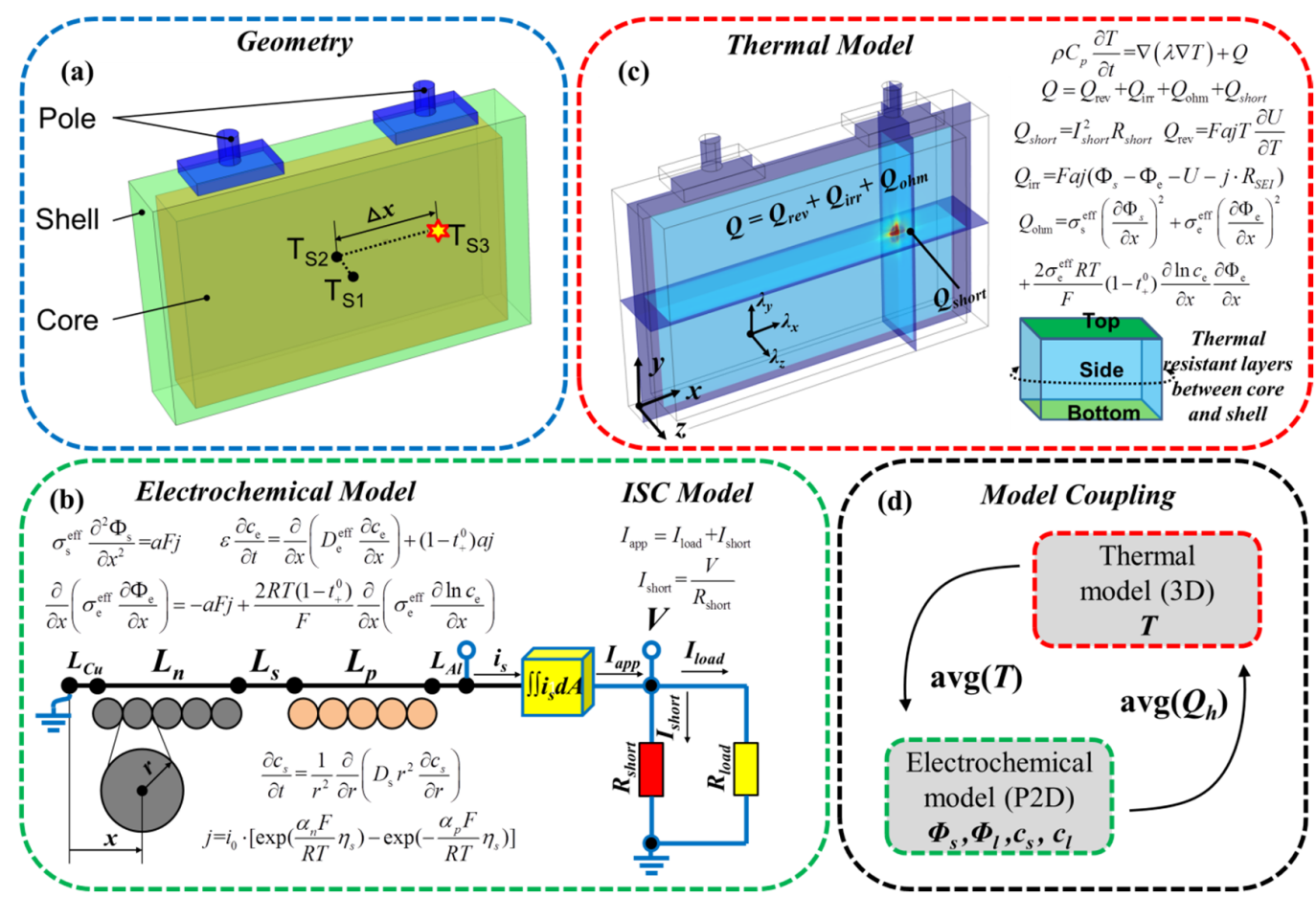

Figure 2 The structure of the et-ISC model in this paper.

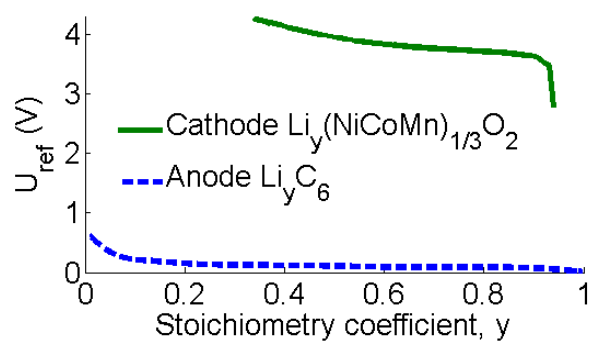

Figure 3 The open circuit potential of the cathode and the anode for the electrochemical model. 


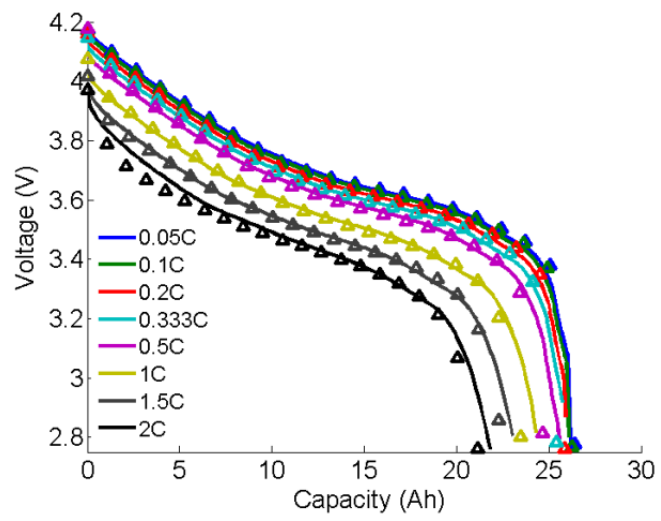

Figure 4 A comparison of the voltage responses at different discharge rates, the electrochemical model (solid lines) and experimental data ( $\Delta$ markers).

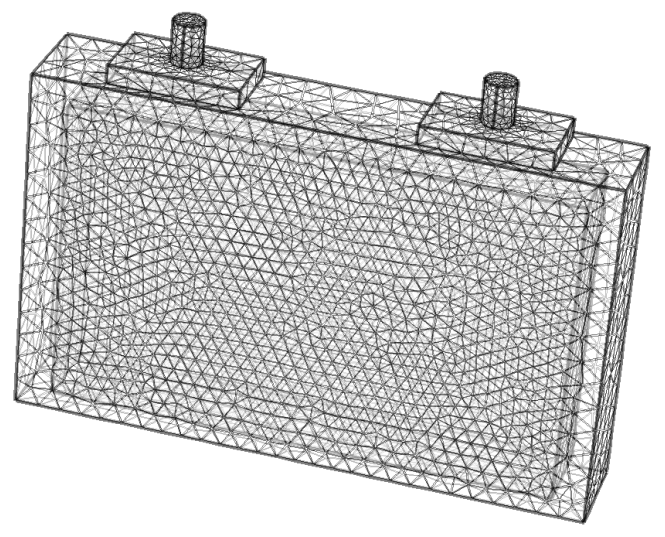

Figure 5 The mesh grids of the 3D thermal model.

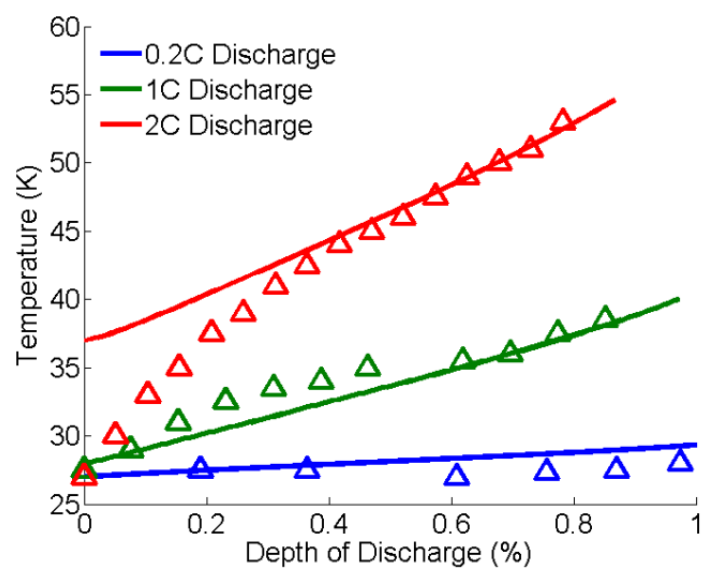

Figure 6 A comparison of the temperature responses at different discharge rates, the thermal model (solid lines) and experimental data in [57] ( $\Delta$ markers). 


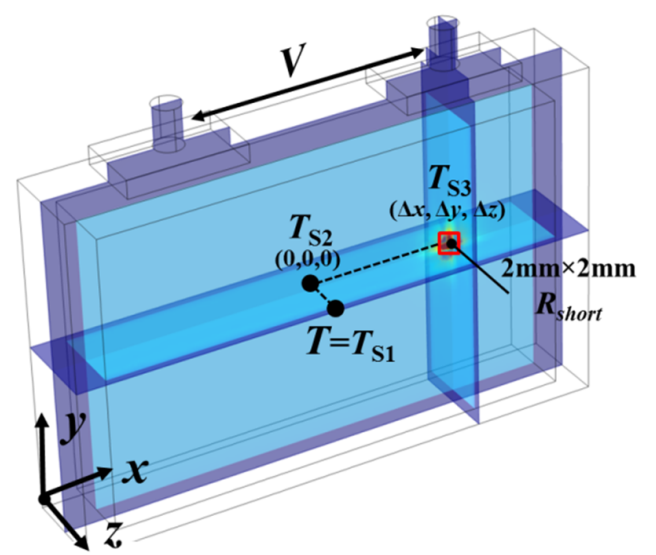

Figure 7 ISC settings in the electrochemical model.

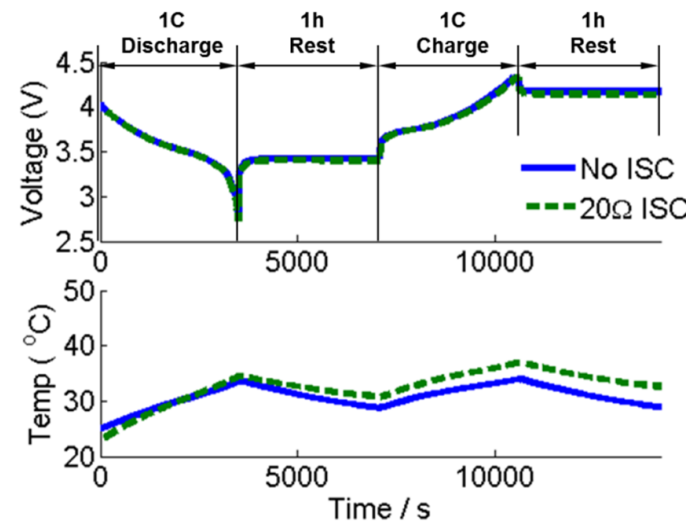

Figure 8 The output of the electrochemical-thermal model with and without ISC under $1 \mathrm{C}$ charge/discharge.

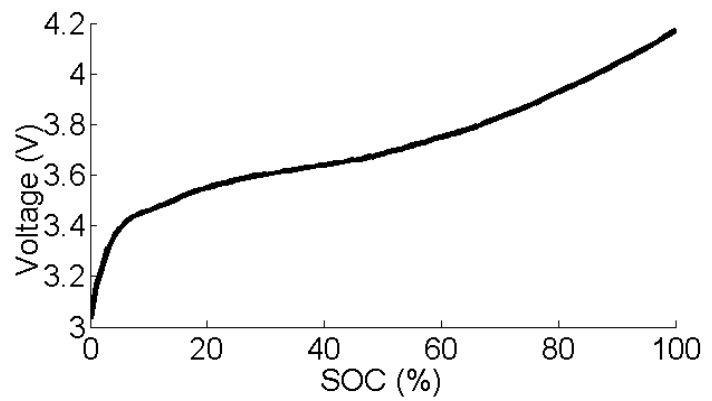

Figure 9 OCV vs. SOC as an output of the electrochemical-thermal model. 

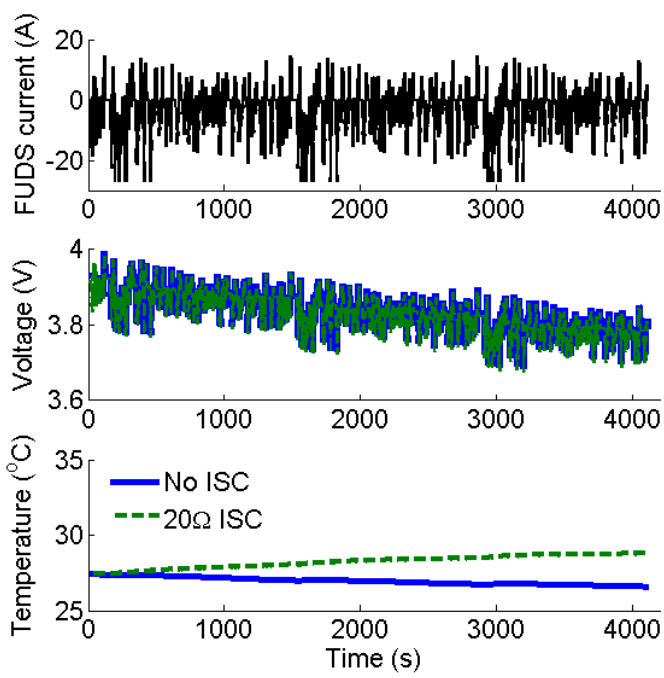

Figure 10 Model output applying FUDS current profile.

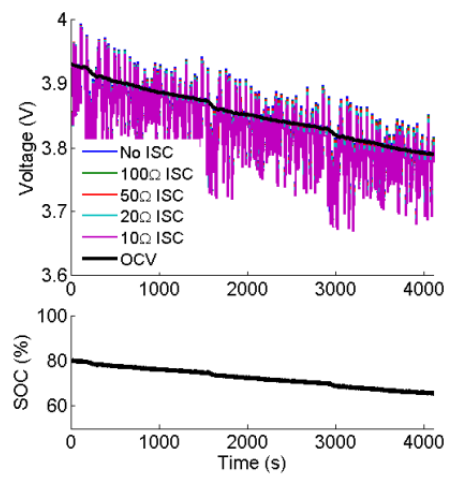

(a) The voltage, OCV, and SOC

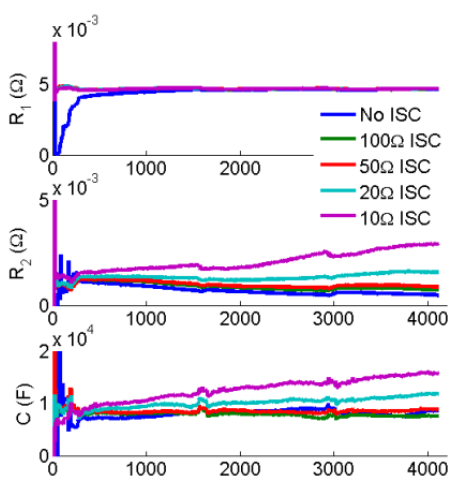

(b) The ECM model based detection results, when $I_{\mathrm{SOC}}=I_{\text {load }}$ in Eqn. (27)

Figure 11 Voltage-related detection results for various degree of ISC.
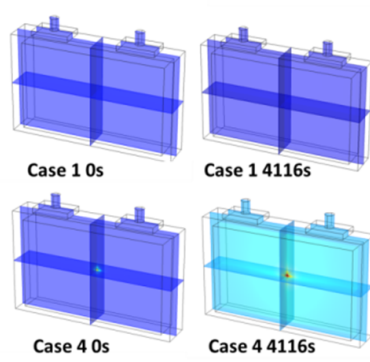

Case $14116 \mathrm{~s}$

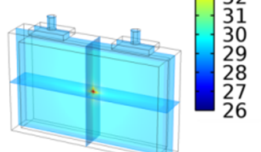

Case 4 4116s

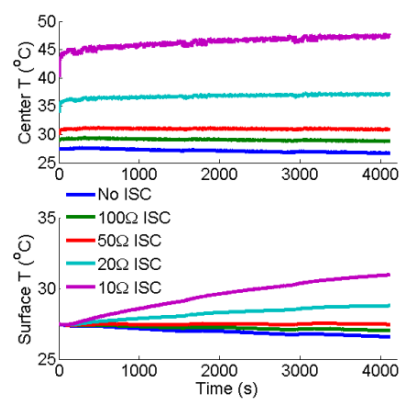

(b) $V, T$ response of the model for Case 1-5

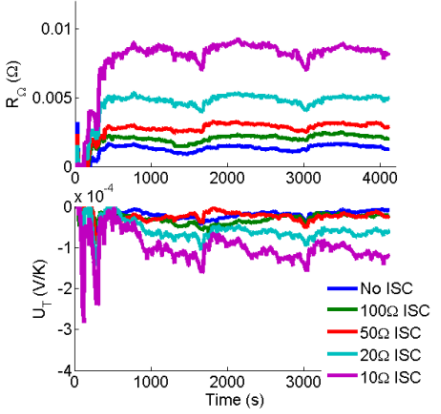

(c) The EBE model based detection results model for Case 1 and 4

Figure 12 Temperature-related detection results for various degree of ISC. 

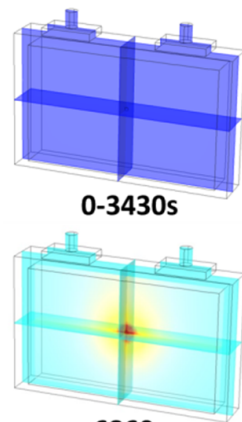

6860s

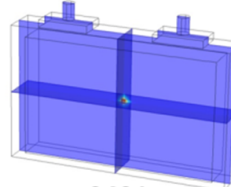

3431s

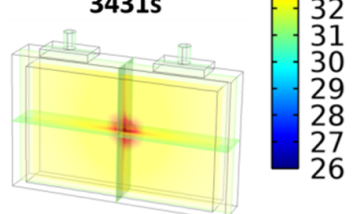

9604s

[ $\left.{ }^{\circ} \mathrm{C}\right]$

35

. 34

32

30

28

27

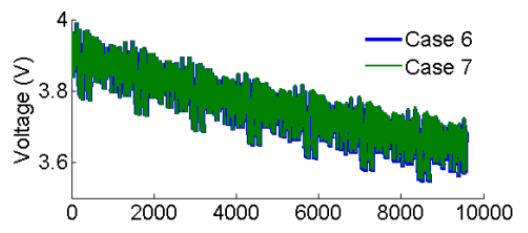

(a) 3D image of ISC in the model for Case 6
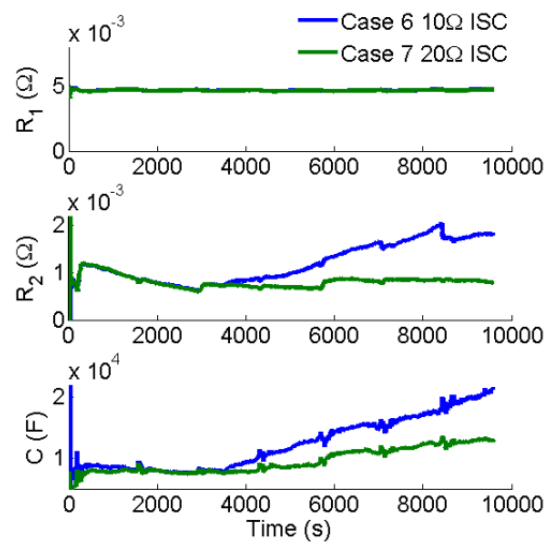

(c) Detection results based on the ECM model

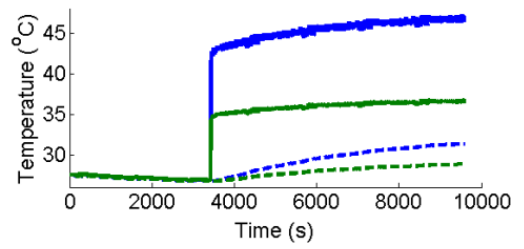

(b) $V, T$ response of the model for Case 6 and 7
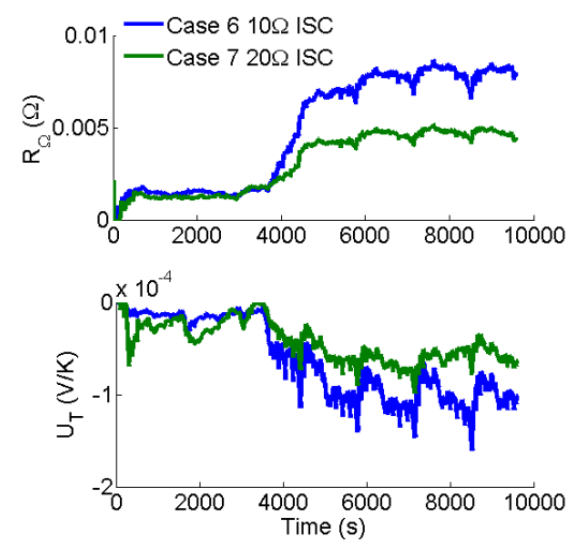

(d) Detection results based on the EBE model

Figure 13 Detection results instantaneously triggered ISC. 


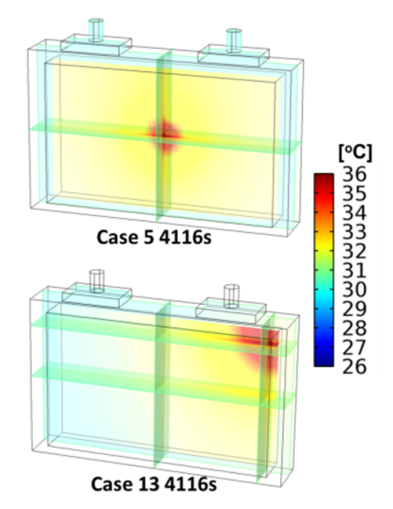

(a) 3D image of ISC in the model

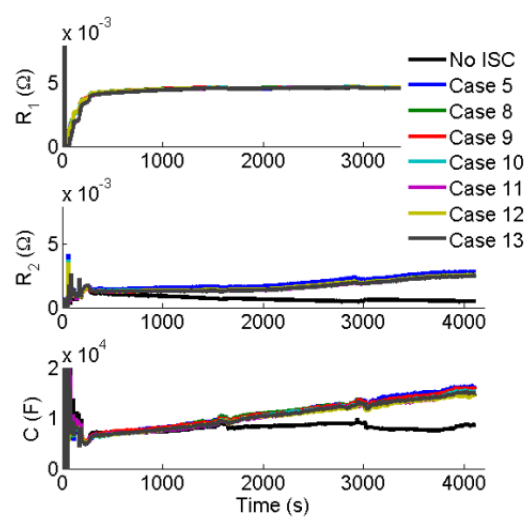

(c) ECM model based detection results

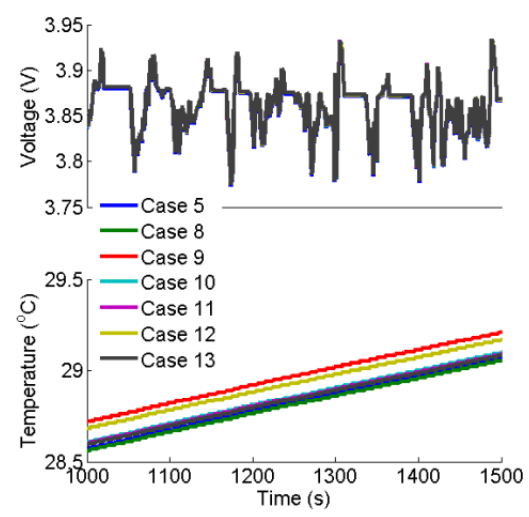

(b) $V, T$ response of the model
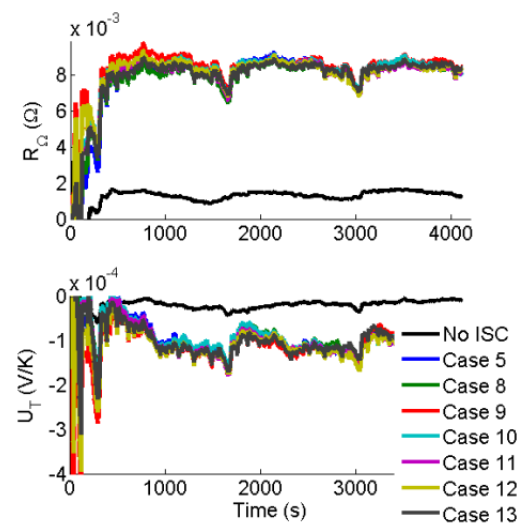

(d) EBE model based detection results

Figure 14 Detection results for ISC at different locations.

(a) Case 5

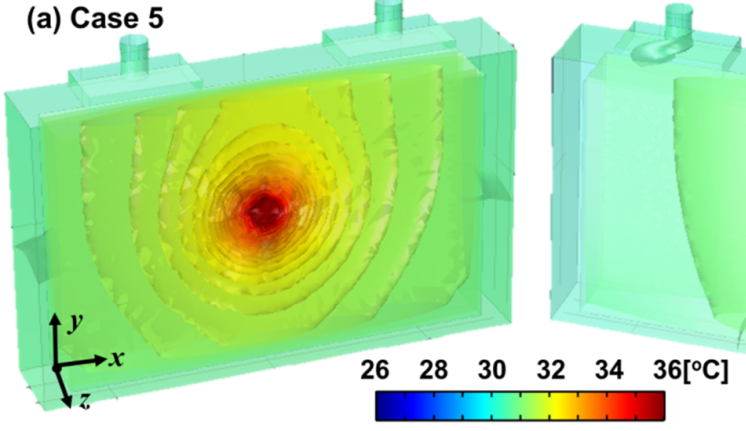

(c)

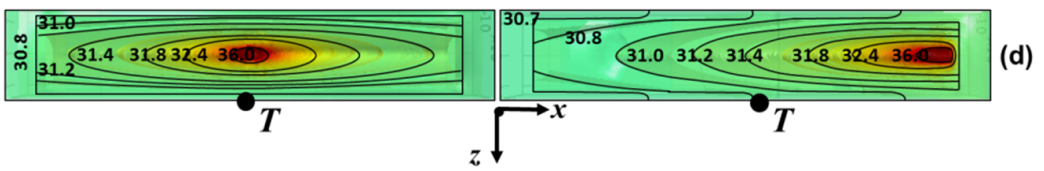

(b) Case 10

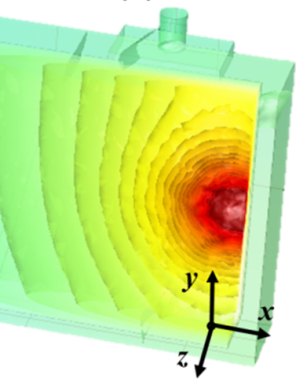

)

Figure 15 Oval temperature distribution in the battery core. 
Table 1 The geometry of the large format battery.

\begin{tabular}{cccc}
\hline Component & Symbol & Parameter Name & Value (m) \\
\hline \multirow{4}{*}{ Shell } & $L_{S}$ & Length & 0.148 \\
& $B_{S}$ & Broad & 0.026 \\
& $H_{S}$ & Height & 0.091 \\
& $L_{C}$ & Length & 0.130 \\
Core & $B_{C}$ & Broad & 0.022 \\
& $H_{C}$ & Height & 0.080 \\
\hline
\end{tabular}


Table 2 The governing equations of the electrochemical model [42]-[57].

\begin{tabular}{|c|c|c|c|}
\hline Equation name & Equation expressions & & Boundary conditions \\
\hline Ohm's law & $-\sigma_{\mathrm{s}}^{\mathrm{eff}} \frac{\partial \Phi_{\mathrm{s}}}{\partial x}=i_{\mathrm{s}}$ & (1) & $-\left.\sigma_{\mathrm{s}}^{\mathrm{eff}} \frac{\partial \Phi_{\mathrm{s}}}{\partial x}\right|_{x=L_{C_{u}}+L_{n}+L_{s}+L_{p}+L_{A l}}=i_{\text {app }}$ \\
\hline Charge, solid phase & $-\frac{\partial i_{\mathrm{s}}}{\partial x}=\sigma_{\mathrm{s}}^{\mathrm{eff}} \frac{\partial^{2} \Phi_{\mathrm{s}}}{\partial x^{2}}=a F j$ & (2) & $-\left.\sigma_{\mathrm{s}}^{\mathrm{eff}} \frac{\partial \Phi_{\mathrm{s}}}{\partial x}\right|_{x=L_{C_{u}}+L_{n}}=-\left.\sigma_{\mathrm{s}}^{\text {eff }} \frac{\partial \Phi_{\mathrm{s}}}{\partial x}\right|_{x=L_{C_{u}}+L_{n}+L_{s}}=0$ \\
\hline $\begin{array}{l}\text { Charge, electrolyte } \\
\text { phase }\end{array}$ & $\frac{\partial}{\partial x}\left(\sigma_{\mathrm{e}}^{\mathrm{eff}} \frac{\partial \Phi_{\mathrm{e}}}{\partial x}\right)=-a F j+\frac{2 R T\left(1-t_{+}^{0}\right)}{F} \frac{\partial}{\partial x}\left(\sigma_{\mathrm{e}}^{\text {eff }} \frac{\partial \ln c_{\mathrm{e}}}{\partial x}\right.$ & (3) & $-\left.\sigma_{\mathrm{e}}^{\mathrm{eff}} \frac{\partial \Phi_{\mathrm{e}}}{\partial x}\right|_{x=L_{C u}}=-\left.\sigma_{\mathrm{e}}^{\mathrm{eff}} \frac{\partial \Phi_{\mathrm{e}}}{\partial x}\right|_{x=L_{C_{u}}+L_{n}+L_{s}+L_{p}}=0$ \\
\hline Species, solid phase & $\frac{\partial c_{s}}{\partial t}=\frac{1}{r^{2}} \frac{\partial}{\partial r}\left(D_{\mathrm{s}} r^{2} \frac{\partial c_{s}}{\partial r}\right)$ & (4) & $-\left.D_{\mathrm{s}} \frac{\partial c_{\mathrm{s}}}{\partial r}\right|_{r=0}=0,-\left.D_{\mathrm{s}} \frac{\partial c_{\mathrm{s}}}{\partial r}\right|_{r=R_{\mathrm{s}}}=j$ \\
\hline $\begin{array}{c}\text { Species, electrolyte } \\
\text { phase }\end{array}$ & $\varepsilon_{\mathrm{e}} \frac{\partial c_{\mathrm{e}}}{\partial t}=\frac{\partial}{\partial x}\left(D_{\mathrm{e}}^{\text {eff }} \frac{\partial c_{\mathrm{e}}}{\partial x}\right)+\left(1-t_{+}^{0}\right) a j$ & (5) & $-\left.D_{\mathrm{e}}^{\mathrm{eff}} \frac{\partial c_{\mathrm{e}}}{\partial x}\right|_{x=L_{C u}}=-\left.D_{\mathrm{e}}^{\mathrm{eff}} \frac{\partial c_{\mathrm{e}}}{\partial x}\right|_{x=L_{C u}+L_{p}+L_{s}+L_{n}}=0$ \\
\hline $\begin{array}{l}\text { Electrical current on } \\
\text { electrode, Butler- } \\
\text { Volmer Equation }\end{array}$ & $j=i_{0} \cdot\left[\exp \left(\frac{\alpha_{n} F}{R T} \eta_{s}\right)-\exp \left(-\frac{\alpha_{p} F}{R T} \eta_{s}\right)\right]$ & (6) & \\
\hline $\begin{array}{l}\text { Over-potential for } \\
\text { the intercalation }\end{array}$ & $\eta_{s}=\Phi_{s}-\Phi_{\mathrm{e}}-U-j \cdot R_{S E I}$ & (7) & \\
\hline $\begin{array}{c}\text { Exchange current } \\
\text { density }\end{array}$ & $i_{0}=k \cdot\left(c_{\mathrm{e}}\right)^{\alpha_{n}}\left(c_{\mathrm{s}, \max }-c_{\mathrm{s}, \mathrm{e}}\right)^{\alpha_{n}}\left(c_{\mathrm{s}, \mathrm{e}}\right)^{\alpha_{p}}$ & (8) & \\
\hline $\begin{array}{l}\text { Local stoichiometry } \\
\text { coefficient } y \text { for the } \\
\text { electrode }\end{array}$ & $y=\frac{3}{R_{s}^{3}} \int_{0}^{R_{s}} r^{2} \frac{c_{\mathrm{s}}}{c_{\mathrm{s}, \max }} d r$ & (9) & \\
\hline $\begin{array}{l}\text { Temperature } \\
\text { dependent open } \\
\text { circuit potential }\end{array}$ & $U=U_{\text {ref }}(y)-\left(T-T_{\text {ref }}\right)\left[\frac{d U}{d T}\right]$ & (10) & \\
\hline
\end{tabular}

Table 3 The variables in the electrochemical model.

\begin{tabular}{clc}
\hline Symbol & \multicolumn{1}{c}{ Description } & Unit \\
\hline$\Phi_{\mathrm{s}}$ & Electrical potential in the solid phase & $\mathrm{V}$ \\
$\Phi_{\mathrm{e}}$ & Electrical potential in the electrolyte phase & $\mathrm{V}$ \\
$c_{\mathrm{s}}$ & Insertion particle concentration in the solid phase & $\mathrm{mol} / \mathrm{m}^{3}$ \\
$c_{\mathrm{e}}$ & Salt concentration in the electrolyte phase & $\mathrm{mol} / \mathrm{m}^{3}$ \\
$j$ & Molar flux & $\mathrm{mol} / \mathrm{m}^{2} \cdot \mathrm{s}$ \\
$i_{s}$ & Electrode current density & $\mathrm{A} / \mathrm{m}^{2}$ \\
\hline
\end{tabular}


Table 4 The physio-electrochemical parameters used in the electrochemical model.

\begin{tabular}{|c|c|c|c|c|c|c|c|}
\hline Symbol & Parameter & Unit & & & Value & & \\
\hline$C_{\text {norm }}$ & $\begin{array}{l}\text { Nominal capacity of the large } \\
\text { format battery }\end{array}$ & $\mathrm{Ah}$ & & & 27 & & \\
\hline$i_{1 \mathrm{C}}$ & $\begin{array}{l}\text { Normalized current density for } \\
\text { 1C charge rate }\end{array}$ & $\mathrm{A} / \mathrm{m}^{2}$ & & & 17 & & \\
\hline$N$ & The number of stacked plates & 1 & & & 152 & & \\
\hline$F$ & Faraday constant & $\mathrm{A} \cdot \mathrm{s} / \mathrm{mol}$ & & & 96485 & & \\
\hline$t_{+}^{0}$ & Transference number & 1 & & & 0.363 & & \\
\hline Symbol & Parameter & Unit & $\mathrm{Cu}$ foil & $\begin{array}{l}\text { Negative } \\
\text { electrode }\end{array}$ & Separator & $\begin{array}{l}\text { Positive } \\
\text { electrode }\end{array}$ & Al foil \\
\hline$L$ & Length & M & $9 \times 10^{-6}$ & $59 \times 10^{-6}$ & $25 \times 10^{-6}$ & $52 \times 10^{-6}$ & $20 \times 10^{-6}$ \\
\hline$\sigma_{\mathrm{s}}^{\mathrm{eff}}$ & $\begin{array}{l}\text { Effective electrical conductivity, } \\
\text { solid phase }\end{array}$ & $\mathrm{S} / \mathrm{m}$ & $\sigma_{\mathrm{s}}$ & $\varepsilon_{\mathrm{s}}^{1.5} \sigma_{\mathrm{s}}$ & & $\varepsilon_{\mathrm{s}}^{1.5} \sigma_{\mathrm{s}}$ & $\sigma_{\mathrm{s}}$ \\
\hline$\sigma_{\mathrm{s}}$ & $\begin{array}{l}\text { Electrical conductivity, solid } \\
\text { phase }\end{array}$ & $\mathrm{S} / \mathrm{m}$ & $5.998 \times 10^{7}$ & 100 & & 3.8 & $3.774 \times 10^{7}$ \\
\hline$\varepsilon_{\mathrm{s}}$ & Volume fraction, solid phase & 1 & & 0.471 & & 0.297 & \\
\hline$\sigma_{\mathrm{e}}^{\mathrm{eff}}$ & $\begin{array}{l}\text { Effective electrical conductivity, } \\
\text { electrolyte phase }\end{array}$ & $\mathrm{S} / \mathrm{m}$ & & $\varepsilon_{\mathrm{e}}^{1.5} \sigma_{\mathrm{e}}$ & $\sigma_{\mathrm{e}}$ & $\varepsilon_{\mathrm{e}}^{1.5} \sigma_{\mathrm{e}}$ & \\
\hline$\sigma_{\mathrm{e}}$ & $\begin{array}{l}\text { Electrical conductivity, } \\
\text { electrolyte phase }\end{array}$ & $\mathrm{S} / \mathrm{m}$ & & $\begin{array}{c}\sigma_{\mathrm{e}}=f\left(c_{e}\right) \\
{[59]}\end{array}$ & $\sigma_{\mathrm{e}}=f\left(c_{e}\right)$ & $\sigma_{\mathrm{e}}=f\left(c_{e}\right)$ & \\
\hline$\varepsilon_{\mathrm{e}}$ & $\begin{array}{l}\text { Volume fraction, electrolyte } \\
\text { phase }\end{array}$ & 1 & & 0.357 & & 0.444 & \\
\hline$D_{\mathrm{s}}$ & Intercalation diffusivity & $\mathrm{m}^{2} / \mathrm{s}$ & & $3.9 \times 10^{-14}$ & & $1 \times 10^{-13}$ & \\
\hline$D_{\mathrm{e}}^{\mathrm{eff}}$ & Effective electrolyte diffusivity & $\mathrm{m}^{2} / \mathrm{s}$ & & $\varepsilon_{\mathrm{e}}^{1.5} D_{\mathrm{e}}$ & $D_{\mathrm{e}}$ & $\varepsilon_{\mathrm{e}}^{1.5} D_{\mathrm{e}}$ & \\
\hline$D_{\mathrm{e}}$ & Electrolyte diffusivity & $\mathrm{m}^{2} / \mathrm{s}$ & & $7.5 \times 10^{-11}$ & $7.5 \times 10^{-11}$ & $7.5 \times 10^{-11}$ & \\
\hline$R_{s}$ & Particle radius & M & & $15 \times 10^{-6}$ & & $15 \times 10^{-6}$ & \\
\hline$A$ & Specific interfacial area & $1 / \mathrm{m}$ & & $3 \varepsilon_{\mathrm{s}} / R_{\mathrm{s}}$ & & $3 \varepsilon_{\mathrm{s}} / R_{\mathrm{s}}$ & \\
\hline$\alpha_{n}, \alpha_{p}$ & Charge transfer coefficient & 1 & & 0.5 & & 0.5 & \\
\hline$R_{S E I}$ & $\begin{array}{l}\text { Resistance of solid electrolyte } \\
\text { interface }\end{array}$ & $\Omega \cdot \mathrm{m}^{2}$ & & 0.001 & & 0.001 & \\
\hline$K$ & Reaction rate coefficient & $\mathrm{m} / \mathrm{s}$ & & $2 \times 10^{-11}$ & & $2 \times 10^{-11}$ & \\
\hline$c_{\mathrm{s}, \max }$ & $\begin{array}{l}\text { Maximum solid phase Li-ion } \\
\text { concentration }\end{array}$ & $\mathrm{mol} / \mathrm{m}^{3}$ & & 31500 & & 72600 & \\
\hline Y & $\begin{array}{l}\text { Stoichiometry coefficient, } y \text { at } \\
100 \% / 0 \% \text { SOC }\end{array}$ & 1 & & $0.80 / 0.05$ & & $0.34 / 0.93$ & \\
\hline$U_{\text {ref }}$ & $\begin{array}{l}\text { Reference open circuit potential } \\
\text { at } T_{\text {ref }}=25^{\circ} \mathrm{C}\end{array}$ & V & & Fig. 3 & & Fig. 3 & \\
\hline$\frac{d U}{d T}$ & $\begin{array}{l}\text { Temperature derivative of } \\
\text { equilibrium potential }\end{array}$ & $\mathrm{V} / \mathrm{K}$ & & -0.00008 & & -0.0001 & \\
\hline
\end{tabular}


Table 5 The governing equations of the thermal model [43], [55]-[57].

\begin{tabular}{|c|c|c|c|}
\hline Equation name & \multicolumn{2}{|l|}{ Equation expressions } & Boundary conditions \\
\hline Energy balance & $\rho C_{p} \frac{\partial T}{\partial t}=\frac{\partial}{\partial x}\left(\lambda_{x} \frac{\partial T}{\partial x}\right)+\frac{\partial}{\partial y}\left(\lambda_{y} \frac{\partial T}{\partial y}\right)+\frac{\partial}{\partial z}\left(\lambda_{z} \frac{\partial T}{\partial z}\right)+Q$ & (13) & $-\left.\lambda_{\text {shell }} \frac{\partial T}{\partial n}\right|_{\text {surface }}=h\left(T-T_{\infty}\right)$ \\
\hline Heat generation & $Q=Q_{\text {rev }}+Q_{\text {irr }}+Q_{\text {ohm }}+Q_{\text {short }}$ & (14) & \\
\hline Reversible heat generation & $Q_{\mathrm{rev}}=F a j T \frac{\partial U}{\partial T}$ & (15) & \\
\hline Irreversible heat generation & $Q_{\mathrm{irr}}=F a j\left(\Phi_{s}-\Phi_{\mathrm{e}}-U-j \cdot R_{S E I}\right)$ & (16) & \\
\hline Ohmic heat generation & $Q_{\mathrm{ohm}}=\sigma_{\mathrm{s}}^{\text {eff }}\left(\frac{\partial \Phi_{s}}{\partial x}\right)^{2}+\sigma_{\mathrm{e}}^{\text {eff }}\left(\frac{\partial \Phi_{\mathrm{e}}}{\partial x}\right)^{2}+\frac{2 \sigma_{\mathrm{e}}^{\mathrm{eff}} R T}{F}\left(1-t_{+}^{0}\right) \frac{\partial \ln c_{\mathrm{e}}}{\partial x}$ & $\frac{\partial \Phi_{\mathrm{e}}}{\partial x}$ & \\
\hline & & (17) & \\
\hline $\begin{array}{l}\text { Joule heat generation, short } \\
\text { circuit }\end{array}$ & $Q_{\text {short }}= \begin{cases}I_{\text {short }}^{2} R_{\text {short }}, & \text { short position } \\
0, & \text { other position }\end{cases}$ & (18) & \\
\hline Thermal resistant layer between & $-\left.\lambda_{\text {core }} \frac{\partial T}{\partial n}\right|_{\substack{\text { corre } \\
\text { surface }}}=\frac{\lambda_{\text {layer }}}{\delta_{\text {layer }}}\left(T_{\text {core }}-T_{\text {shell }}\right)$ & (19) & \\
\hline the core and the shell & $-\left.\lambda_{\text {shell }} \frac{\partial T}{\partial n}\right|_{\substack{\text { core } \\
\text { surface }}}=\frac{\lambda_{\text {layer }}}{\delta_{\text {layer }}}\left(T_{\text {shell }}-T_{\text {core }}\right)$ & (20) & \\
\hline
\end{tabular}

Table 6 The physical parameters used in the thermal model.

\begin{tabular}{|c|c|c|c|c|c|c|c|}
\hline Symbol & Parameter & Unit & Core & Shell & $\begin{array}{l}\text { Core } \\
\text { Top }\end{array}$ & $\begin{array}{c}\text { Core } \\
\text { Side \& } \\
\text { Bottom }\end{array}$ & Ambience \\
\hline$\lambda_{i}$ & $\begin{array}{l}\text { Thermal conductivity. } \\
\text { The subscript } i=\{\text { core, shell }\} \\
\text { denotes the component in the } \\
\text { model; } \\
i=\{x, y, z\} \text { denotes the } \\
\text { direction of heat conduction. }\end{array}$ & $\mathrm{W} / \mathrm{m} \cdot \mathrm{K}$ & $\begin{array}{c}\lambda_{x}=\lambda_{y}=21, \\
\lambda_{z}=0.5 \\
{[61]}\end{array}$ & $\begin{array}{c}\lambda_{x}=\lambda_{y}=\lambda_{z}=160 \\
\text { (Aluminum[63]) }\end{array}$ & & & \\
\hline$\rho$ & The density & $\mathrm{kg} / \mathrm{m}^{3}$ & 2100 & 2700 & & & \\
\hline$C_{p}$ & The specific thermal capacity & $\mathrm{J} / \mathrm{kg} \cdot \mathrm{K}$ & 1100 & 900 & & & \\
\hline$\lambda_{\text {layer }}$ & $\begin{array}{l}\text { Thermal conductivity of the } \\
\text { thin thermal resistant layer. }\end{array}$ & $\mathrm{W} / \mathrm{m} \cdot \mathrm{K}$ & & & $\begin{array}{c}0.026 \\
(\text { air } \\
\left.25^{\circ} \mathrm{C}\right) \\
{[64]}\end{array}$ & $\begin{array}{c}0.28 \\
\text { (Al-plastic } \\
\text { film) [61] }\end{array}$ & \\
\hline Slayer & $\begin{array}{l}\text { Thickness of the thin thermal } \\
\text { resistant layer. }\end{array}$ & $\mathrm{m}$ & & & 0.005 & 0.001 & \\
\hline$h$ & Convection coefficient & $\mathrm{W} / \mathrm{m}^{2} \cdot \mathrm{K}$ & & & & & 5 \\
\hline$T_{\infty}$ & Ambient temperature & ${ }^{\circ} \mathrm{C}$ & & & & & 25 \\
\hline
\end{tabular}


Table 7 The parameters used in the parameter estimation algorithm.

\begin{tabular}{clcc}
\hline Symbol & \multicolumn{1}{c}{ Parameter } & Unit & Value \\
\hline$t_{\mathrm{s}}$ & The sampling time or the output time interval in Comsol simulation & $\mathrm{s}$ & 1 \\
$M$ & The lumped mass of the battery & $\mathrm{kg}$ & 0.72 \\
$C_{\mathrm{p}}$ & The lumped specific heat capacity of the battery & $\mathrm{J} / \mathrm{kg} \cdot \mathrm{K}$ & 1100 \\
$h$ & The lumped convective coefficient & $\mathrm{W} / \mathrm{m}^{2} \cdot \mathrm{K}$ & 5 \\
$A$ & The total surface area of the battery & $\mathrm{m}^{2}$ & 0.04 \\
$T_{\infty}$ & The ambient temperature & ${ }^{\circ} \mathrm{C}$ & 25 \\
$X$ & The constant factor for estimating internal temperature & 1 & 0.06 \\
$n$ & The points used to get the temperature derivative $\dot{T}_{\mathrm{sl}}(k)$ & 1 & 30 \\
$\beta$ & The forgetting factor for the RLS algorithm & 1 & 0.999 \\
$I_{\text {Pstop }}$ & The current limit for covariance updating stop & $\mathrm{A}$ & 20 \\
$\Sigma_{V}$ & The standard deviation of the Gaussian noise applied on the voltage signal & $\mathrm{mV}$ & 2 \\
$\Sigma_{T}$ & The standard deviation of the Gaussian noise applied on the temperature signal & ${ }^{\circ} \mathrm{C}$ & 0.1 \\
\hline
\end{tabular}

Table 8 ISC cases for testing the detection algorithm.

\begin{tabular}{cccccc}
\hline Case & $\begin{array}{c}\text { FUDS } \\
\text { Cycle No. }\end{array}$ & Total time [s] & $\boldsymbol{R}_{\text {short }}[\boldsymbol{\Omega}]$ & $\begin{array}{c}\text { ISC position } \\
(\Delta \boldsymbol{x}, \Delta \boldsymbol{y}, \Delta \boldsymbol{z})[\mathbf{m m}]\end{array}$ & $\begin{array}{c}\operatorname{Max}\left\{\boldsymbol{T}=\boldsymbol{T}_{\mathbf{S} 3}\right\} \text { at } \\
\text { ISC point }\left[{ }^{\circ} \mathbf{C}\right]\end{array}$ \\
\hline $\mathbf{1}$ & 3 & 4116 & $\infty$ & No ISC & 27.59 \\
$\mathbf{2}$ & 3 & 4116 & 100 & $(0,0,0)$ & 29.39 \\
$\mathbf{3}$ & 3 & 4116 & 50 & $(0,0,0)$ & 31.21 \\
$\mathbf{4}$ & 3 & 4116 & 20 & $(0,0,0)$ & 36.96 \\
$\mathbf{5}$ & 3 & 4116 & 10 & $(0,0,0)$ & 48.00 \\
$\mathbf{6}$ & 5 & 6860 & $0(k<=3430 \mathrm{~s})$ & $(0,0,0)$ & 46.38 \\
& & & $10(k>3430 \mathrm{~s})$ & & \\
$\mathbf{7}$ & 5 & 6860 & $0(k<=3430 \mathrm{~s})$ & $(0,0,0)$ & 36.44 \\
$\mathbf{8}$ & 3 & 4116 & 10 & $(0,0,-5)$ & 49.93 \\
$\mathbf{9}$ & 3 & 4116 & 10 & $(0,0,5)$ & 50.92 \\
$\mathbf{1 0}$ & 3 & 4116 & 10 & $(60,0,0)$ & 51.47 \\
$\mathbf{1 1}$ & 3 & 4116 & 10 & $(60,0,-5)$ & 51.98 \\
$\mathbf{1 2}$ & 3 & 4116 & 10 & $(60,0,5)$ & 52.17 \\
$\mathbf{1 3}$ & 3 & 4116 & 10 & $(60,30,-5)$ & 53.18 \\
\hline
\end{tabular}

Table 9 Initial conditions for the ISC simulations.

\begin{tabular}{ccccc}
\hline & $\boldsymbol{S O C}(0)$ & $\boldsymbol{x}$ in $\mathrm{Li}_{x} \mathrm{C}_{6}$ & $\boldsymbol{y}$ in $\mathrm{Li}_{y}\left(\mathrm{NiCoMn}_{\mathbf{1} / 3} \mathrm{O}_{\mathbf{2}}\right.$ & Initial temperature $\boldsymbol{T ( 0 )}\left[{ }^{\circ} \mathrm{C}\right]$ \\
\hline Value & $80 \%$ & 0.649 & 0.458 & 27.5 \\
\hline
\end{tabular}


Table 10 Detection results for various degrees of ISC.

\begin{tabular}{ccccccc}
\hline \multirow{2}{*}{ Case } & \multirow{2}{*}{$\boldsymbol{R}_{\text {short }}[\boldsymbol{\Omega}]$} & \multicolumn{5}{c}{ Average value in the last FUDS cycle, $\boldsymbol{k} \in[\mathbf{2 7 4 5 , 4 1 1 6 ] \mathbf { s }}$} \\
\cline { 3 - 7 } & $\boldsymbol{R}_{\mathbf{1}}[\mathbf{m} \boldsymbol{\Omega}]$ & $\boldsymbol{R}_{\mathbf{2}}[\mathbf{m} \boldsymbol{\Omega}]$ & $\boldsymbol{C}[\mathbf{F}]$ & $\boldsymbol{R}_{\boldsymbol{\Omega}}[\mathbf{m} \boldsymbol{\Omega}]$ & $\boldsymbol{U}_{\boldsymbol{T}}[\mathbf{m} \mathbf{V} / \mathbf{K}]$ \\
\hline 1 & $\infty$ & 4.6 & 0.55 & 8158 & 1.4 & -0.0153 \\
2 & 100 & 4.7 & 0.78 & 7528 & 2.2 & -0.0230 \\
3 & 50 & 4.7 & 0.91 & 8522 & 2.9 & -0.0255 \\
4 & 20 & 4.7 & 1.50 & 11003 & 4.8 & -0.0660 \\
5 & 10 & 4.7 & 2.50 & 14544 & 8.3 & -0.1128 \\
\hline
\end{tabular}

Table 11 Detection results for instantaneously triggered ISC.

\begin{tabular}{ccccccc}
\hline \multirow{2}{*}{ Case } & FUDS & \multicolumn{5}{c}{ Average value in one FUDS cycle } \\
\cline { 2 - 7 } & Cycle No. & $\boldsymbol{R}_{\mathbf{1}}[\mathbf{m} \boldsymbol{\Omega}]$ & $\boldsymbol{R}_{\mathbf{2}}[\mathbf{m} \boldsymbol{\Omega}]$ & $\boldsymbol{C}[\mathbf{F}]$ & $\boldsymbol{R}_{\boldsymbol{\Omega}}[\mathbf{m} \boldsymbol{\Omega}]$ & $\boldsymbol{U}_{\boldsymbol{T}}[\mathbf{m V} / \mathbf{K}]$ \\
\hline & 1 & $/$ & $/$ & $/$ & $/$ & $/$ \\
& 2 & 4.7 & 0.78 & 7939 & 1.5 & -0.017 \\
$\mathbf{6}$ & 3 & 4.7 & 0.75 & 8313 & 1.9 & -0.027 \\
& 4 & 4.6 & 0.95 & 11266 & 6.1 & -0.081 \\
& 5 & 4.6 & 1.40 & 14372 & 7.6 & -0.101 \\
& 6 & 4.7 & 1.70 & 16268 & 8.0 & -0.101 \\
& 7 & 4.7 & 1.80 & 19442 & 7.9 & -0.104 \\
& 1 & $/$ & $/$ & $/$ & $/$ & $/$ \\
& 2 & 4.7 & 0.76 & 7827 & 1.2 & -0.028 \\
7 & 3 & 4.7 & 0.71 & 7731 & 1.7 & -0.018 \\
& 4 & 4.6 & 0.69 & 8508 & 3.8 & -0.050 \\
& 5 & 4.6 & 0.81 & 10478 & 4.6 & -0.064 \\
& 6 & 4.6 & 0.84 & 11571 & 4.7 & -0.064 \\
& 6 & 4.7 & 0.83 & 12656 & 4.7 & -0.055 \\
\hline
\end{tabular}

Table 12 Detection results for ISC at different locations.

\begin{tabular}{cccccc}
\hline \multirow{2}{*}{ Case } & \multicolumn{4}{c}{ Average value in the last FUDS cycle, $\boldsymbol{k} \in[\mathbf{2 7 4 5 , 4 1 1 6 ] \mathbf { s }}$} \\
\cline { 2 - 6 } & $\boldsymbol{R}_{\mathbf{1}}[\mathbf{m} \boldsymbol{\Omega}]$ & $\boldsymbol{R}_{\mathbf{2}}[\mathbf{m} \boldsymbol{\Omega}]$ & $\boldsymbol{C}[\mathrm{F}]$ & $\boldsymbol{R}_{\boldsymbol{\Omega}}[\mathbf{m} \boldsymbol{\Omega}]$ & $\boldsymbol{U}_{\boldsymbol{T}}[\mathbf{m V} / \mathrm{K}]$ \\
\hline $\boldsymbol{1}$ & 4.6 & 0.55 & 8158 & 1.4 & -0.0153 \\
$\mathbf{5}$ & 4.7 & 2.50 & 14544 & 8.3 & -0.1128 \\
$\boldsymbol{8}$ & 4.7 & 2.30 & 13784 & 8.3 & -0.1050 \\
$\mathbf{9}$ & 4.7 & 2.20 & 14135 & 8.5 & -0.1048 \\
$\mathbf{1 0}$ & 4.7 & 2.20 & 13620 & 8.4 & -0.1103 \\
$\mathbf{1 1}$ & 4.7 & 2.20 & 13272 & 8.2 & -0.1143 \\
$\mathbf{1 2}$ & 4.7 & 2.30 & 13167 & 8.2 & -0.1185 \\
$\mathbf{1 3}$ & 4.6 & 2.20 & 13583 & 8.4 & -0.1035 \\
\hline
\end{tabular}

